\title{
A qualitative study of pre -service teachers using co -teaching as a method to understand scientific process skills to teach *inquiry
}

Jennifer Carter McCain

West Virginia University

Follow this and additional works at: https://researchrepository.wvu.edu/etd

\section{Recommended Citation}

McCain, Jennifer Carter, "A qualitative study of pre -service teachers using co -teaching as a method to understand scientific process skills to teach *inquiry" (2005). Graduate Theses, Dissertations, and Problem Reports. 3433.

https://researchrepository.wvu.edu/etd/3433

This Dissertation is protected by copyright and/or related rights. It has been brought to you by the The Research Repository @ WVU with permission from the rights-holder(s). You are free to use this Dissertation in any way that is permitted by the copyright and related rights legislation that applies to your use. For other uses you must obtain permission from the rights-holder(s) directly, unless additional rights are indicated by a Creative Commons license in the record and/ or on the work itself. This Dissertation has been accepted for inclusion in WVU Graduate Theses, Dissertations, and Problem Reports collection by an authorized administrator of The Research Repository @ WVU.

For more information, please contact researchrepository@mail.wvu.edu. 
A Qualitative Study of Pre-service Teachers Using Co-teaching as a Method to Understand Scientific Process Skills to Teach Inquiry

Jennifer Carter McCain

Dissertation submitted to the College of Human Resources and Education at West Virginia University in partial fulfillment of the requirements

for the degree of

\title{
Doctor of Education
}

In

Curriculum and Instruction

\author{
Patricia A. Obenauf, Ed.D., Chair \\ Ronald V. Iannone, Ed.D. \\ Perry Phillips, Ed.D. \\ Linda Spatig, Ed.D. \\ Samuel F. Stack, Ph.D. \\ Department of Educational Theory and Practice
}

\author{
Morgantown, West Virginia \\ 2005
}

Keywords: Co-teaching, Pre-service teachers, Science process skills

Copyright 2005 Jennifer C. McCain 


\section{ABSTRACT \\ A Qualitative Study of Pre-service Teachers Using Co-teaching as Method to Understand Scientific Process Skills to Teach Inquiry}

Jennifer Carter McCain

The National Science Education Standards (NSES) have established scientific literacy as a goal for all students. The goals advocate scientific inquiry as an instructional strategy to be used in the classroom, and standards of inquiry have even been established. At the same time, co-teaching has become prevalent in classroom as regular education teachers work with special education teachers. The classrooms are inclusive and both teachers are to work together to benefit all the students. Research has shown positive perceptions and negative perceptions of co-teaching. In this study, pre-service teachers are co-taught an elementary science methods course at a medium-sized university. They are co-taught the basic science process skills by two science education instructors. In turn, they teach lessons to the methods course with a co-teaching partner covering the basic science process skills. The pre-service teachers were studied to see how they developed an understanding of the process skills and of co-teaching. The results showed how the preservice teachers learned the process skills and how they learned about co-teaching. The co-teaching experience was particularly useful in that the pre-service teachers expressed the roles that co-teachers assume when they are in the classroom. This study shows that pre-service teachers should be made aware of co-teaching at the preparatory level and be able to practice co-teaching before being expected to know how to co-teach when they reach a classroom of their own. 
To my loving husband-your support and love gave me hope and confidence to keep writing.

To my dear parents-your everlasting care and love gives me strength in all I that I do and all that I am. 


\section{ACKNOWLEDGEMENTS}

There are many to thank for all of their support along the way of this journey. To begin, I wish to thank my committee chairperson, Dr. Pat Obenauf, for her enduring patience and encouragement. She took me as a doctoral student when I felt that I had no where else to turn. For that, I will be forever grateful.

I wish to thank Dr. Ron Iannone whose wisdom has caused me to question so many things that I once thought I knew. His way of looking at all things as phenomena and his interest in the spirit of the person has inspired me to seek to understand and not just assume that I already do.

I also wish to thank my fellow South Carolinian, Dr. Sam Stack. He opened my mind to the foundations of education, but also made me see that education is a personal journey through his stories about his young son and family.

I owe a warm thank you to Dr. Perry Phillips as well. He knew nothing about me, and he was willing to take me on as a student upon Dr. Obenauf's encouragement. That dedication to students is immeasurable, but also the professional respect he showed for Dr. Obenuaf shows his impeccable integrity as a true teacher.

My committee would not have been complete without Dr. Linda Spatig. Her time, patience, guidance and support will never be forgotten. Dr. Spatig has a remarkable talent for taking my writing and making it so very much better than I thought it could be. She is an intelligent and warm person, and I am lucky to also call her a colleague.

My study would not have been possible without Dr. Edna Meisel, my co-teacher in the study. Her smile lit up the room when we taught, but it was her insight that led me 
to complete the study. Thank you Edna! Also, the study would have no data without the pre-service teachers in the methods course. They know who they are, and I hope they know how much I appreciate their willingness to participate. 


\section{TABLE OF CONTENTS}

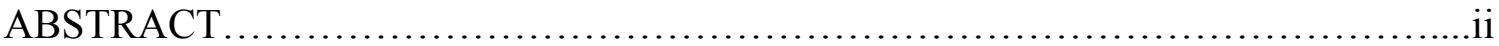

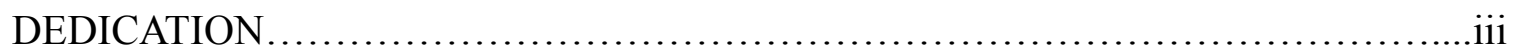

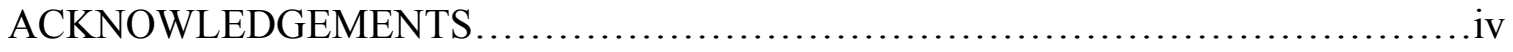

TABLE OF CONTENTS ......................................................vi

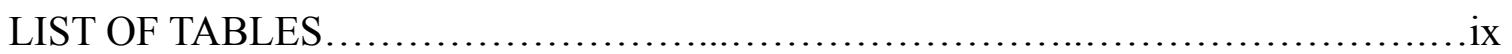

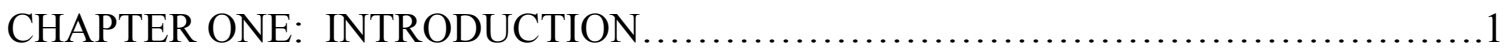

Introduction of the Problem: Inquiry and Co-teaching........................

Problem Statement....................................................4

Purpose of the Study ................................................ 5

Significance of the Study..............................................6

Definition of Terms....................................................6

Assumptions and Limitations........................................ 8

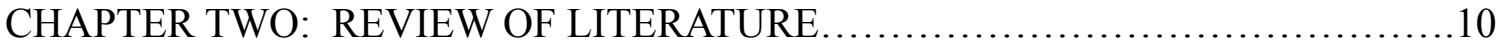

Historical Context................................................... 10

Efforts to Improve Science Education.................................11

Translation to Pre-service Teachers..................................... 13

Research Question One................................................14

What are process skills?........................................................... 14

Importance of process skills....................................16

Assessing the science process skills.................................17

Research Question Two................................................18

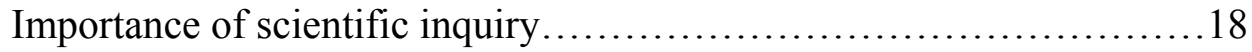

Myths and perceptions of inquiry ................................22

Research Question Three..............................................23

Emergence of co-teaching....................................23

Defining co-teaching.............................................24

How does one know co-teaching is occurring?...................................25

Heuristics of co-teaching from the Roth and Tobin Studies..............28

Research Question Four..............................................29

Considerations with co-teaching ...............................29 
Perceptions of co-teaching..........................................

Research Question Five ................................................ 36

Gap between theory and praxis..................................... 36

Perceptions on learning co-teaching and praxis in the actual classroom...38

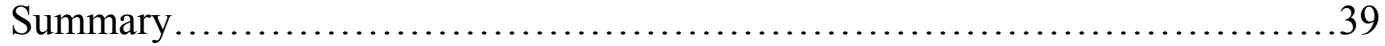

CHAPTER THREE: METHODS..................................................... 42

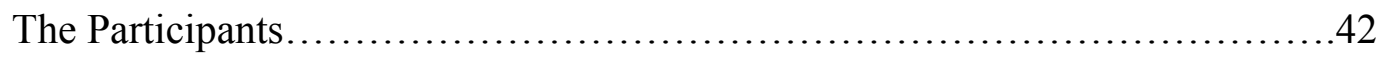

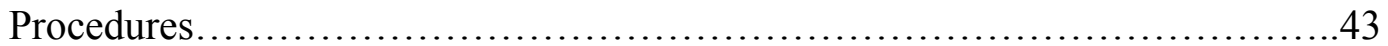

Responses Collected.....................................................45

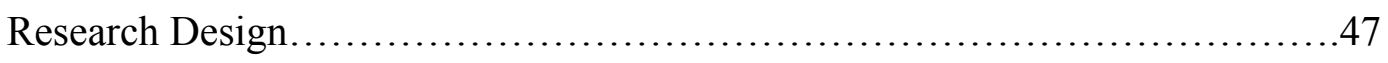

Analysis of the Responses..................................................48

Validity and Credibility ............................................... 50

Confidentiality and Ethical Considerations....................................51

CHAPTER FOUR: ANALYSIS OF THE RESPONSES ..........................53

Research Question One...............................................53

Defining the process skills.........................................54

Process skills as useful tools of society ...............................54

Learning as a rewarding challenge.................................56

Learning through experience......................................58

Research Question Two...............................................60

Process skill as a necessity..........................................61

Process skill instruction as a necessity...............................61

Process skills in the classroom............................................62

Research Question Three ...............................................63

Co-teacher as emotional supporter...................................64

Co-teacher as materials manager......................................64

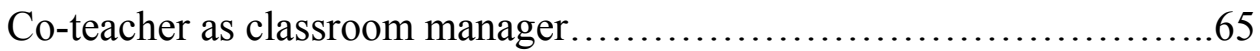

Co-teacher as creative consultant...................................67

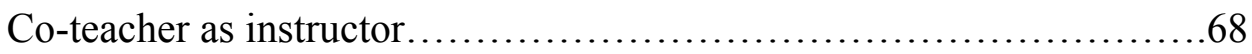

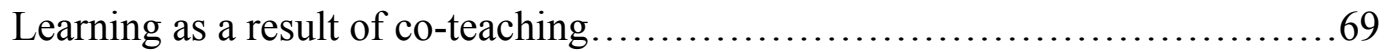

Research Question Four................................................ 71 
Perceptions as Observers..............................................

Perceptions of planning when co-teaching.............................73

Perceptions of presenting when co-teaching............................75

Research Question Five .............................................. 77

CHAPTER FIVE: CONCLUSIONS.............................................. 79

Developing an Understanding of Process Skills...............................79

Perception of Process Skills................................................. 81

Developing an Understanding of Co-teaching............................... 83

Learning with Co-teaching.............................................. 87

Perceptions of Co-teaching ............................................ 88

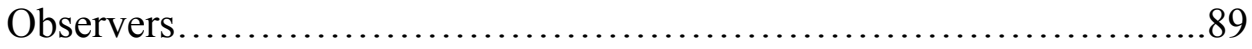

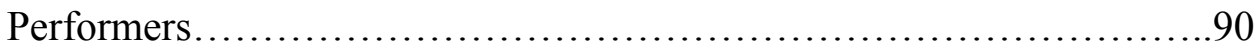

Gap Between Theory and Praxis......................................... 92

Implications for Use in Science Education................................93

Implications for Future Study .......................................... 95

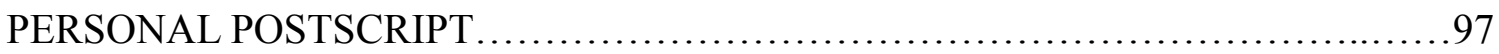

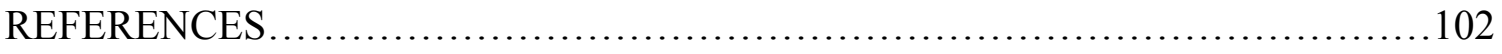

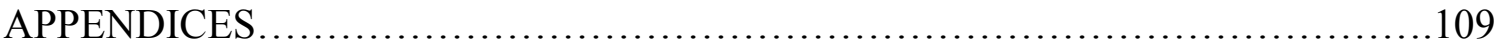

Appendix A: NSES Science Teaching Standards.............................109

Appendix B: NSES Science Education Program Standards.....................111

Appendix C: Science Content Standards and Objective for West Virginia......113

Appendix D: Semi-structured Interview Questions..........................116

Appendix E: Consent and Information Form..............................117

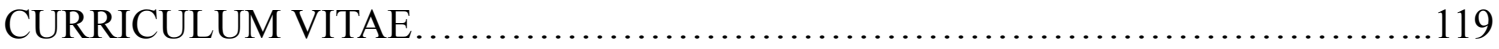




\section{LIST OF TABLES}

TABLE A: AGE GROUPS OF THE PARTICIPANTS ...........................43

TABLE B: PREPARATION LEVEL OF THE PARTICIPANTS ....................43

TABLE C: GENDER OF PARTICIPANTS ...................................43

TABLE D: HOW THE RESEARCH QUESTIONS ARE ANSWERED WITH THE

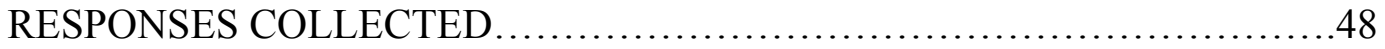




\section{CHAPTER ONE}

\section{Introduction}

Introduction of the Problem: Inquiry and Co-teaching

In the Call to Action of the National Science Education Standards, Klausner and Alberts (1996) claim that the nation has established scientific literacy as a goal for all students. To this end, the National Science Education Standards were written. They are a "roadmap" and they "spell out a vision" of science education in our nation (p. ix). Since science is crucial to our society, scientific literacy must be fostered and developed in all students, be they future scientists or not. All students, according to Klausner and Alberts, have the right to be scientifically literate.

The National Science Education Standards (NSES) list goals for students in school science. The goals advocate inquiry-oriented teaching strategies and opportunities for students to make their own decisions in the science classroom. The goals are:

- "Experience the richness and excitement of knowing about and understanding the natural world;

- Use appropriate scientific processes and principles in making personal decisions;

- Engage intelligently in public discourse and debate about matters of scientific and technological concern; and

- Increase their economic productivity through the use of the knowledge, understanding, and skills of the scientifically literate person in their careers" (1996, p.13).

It is these goals of school science that will drive the future of science education in school classrooms as well as university classes where pre-service teachers are taught how 
to teach science. Kelly (2000) writes in her study that pre-service teachers are mostly only exposed to science taught by lecture mode. Current best practice, according to the NSES, is not lecture mode, and therefore the pre-service teachers are not taught science the way they should in turn teach science. Pre-service teachers must be the ones to make the change in the future to develop science education into the vision that the NSES presents.

The vision of the NSES is one where inquiry is fostered in the classroom as much as possible. According to the NSES, inquiry "refers to the diverse ways in which scientists study the natural world and propose explanations based on the evidence derived from their work" (p. 23, 1996). Inquiry involves making decisions and dialoguing to reach a possible explanation for an event. It is the way scientists gather information that benefits society and should be the way science is taught in the classroom. In order to perform inquiry in the classroom, the students must possess certain skills that are part of scientific inquiry. These skills are referred to as science process skills. The basic process skills to be used in this study are: observing, measuring, inferring, classifying, predicting, and communicating (Padilla, 1990).

Research has shown that co-teaching leads to enhanced learning by the participants (Austin, 2001; Eick et al., 2003; Harris \& Harvey, 2000; Kirkwood-Tucker \& Bleicher, 2003; Lonning \& DeFranco, 1994; Roth \& Tobin, 2001; Thomas \& McRobbie, 2002; Vaughn, Schumm, \& Arquelles, 1997). Co-teaching began in classrooms as a tool used by special educators in accordance with meeting the needs of disabled students (Gately \& Gately, 2001). Recently, co-teaching has been studied by Wolff-Michael Roth and Kenneth Tobin in public schools to enhance the learning of the students and teachers 
(Roth, 1998; Roth \& Tobin, 2001). These researchers have taken their time to spend in classrooms encouraging teaching professionals to work together. These researchers have become the teachers as well, taking a stand in their research. It is their research on mainstream co-teaching that is the inspiration for this study.

Because of this recent research, co-teaching has also emerged in universities with a clinical experiences handbook written to explain co-teaching techniques to their clinical students (Co-Teaching). Co-teaching is not just for special education even in a university setting. Co-teaching is also found in the university-level classroom, specifically a science methods class where the pre-service teachers learn co-teaching and then work with experienced teachers in the public schools. It has been shown that students respond favorably to co-teaching in the public schools in a regular education classroom (Eick, Ware, \& Williams, 2003).

Further, in the study by Eick et al (2003), pre-service teachers who co-taught with a classroom teacher cited eight positive outcomes of co-teaching. They are:

- Support of another professional;

- Comfort with another professional in the classroom;

- Opportunity for critical reflection to modify lesson;

- Opportunity to learn from a professional;

- Development of confidence and assertiveness;

- More focus on teaching and not planning;

- Discovering that inquiry is possible and does work in a classroom; and

- Communication 


\section{Problem Statement}

In this study, I wanted to study the perceptions of pre-service teachers as they perform inquiry-oriented strategies by using science process skills, but using another strategy called co-teaching as a vehicle to enhance their understanding of these process skills. Co-teaching is when two or more teachers are present in a classroom instructing the students. There are many types of co-teaching, but the basic premise in this study is that there is more than one teacher providing the instruction.

Co-teaching has become prevalent in classrooms other than special education, and with this study I wanted to find out if it can be successful in a regular education classroom as well. To sum, it is this statement by educational researchers Roth and Tobin that illuminates what is pertinent to my study. Roth and Tobin (2001) co-taught with a science classroom teacher and a pre-service teacher in an inner city high school. They write, "Co-teaching... provided us many opportunities to learn the subject matter and subject matter pedagogy" (p.241).

This study is of particular interest to me due to my previous employment in a university as a supervisor of teacher education clinical experiences. When I am in a classroom observing a pre-service teacher, I cannot help but be a part of the classroom in a teaching capacity. If a student is having difficulty with their work or if a group of students working together have questions, I make myself available to them. I feel that it is part of my responsibility to make sure all students are being assisted in a classroom. I cannot make the comment to the pre-service teacher later by saying that a particular student or group of students needed additional assistance after the fact. I believe that is only hurting the students. I want to be there to assist in any way I can. 
Co-teaching is, then, what I am instinctively doing in the classroom when I observe. I am actively involved in the lesson and assisting students in practicing the knowledge. I also have been asked to contribute what I may know about a particular subject. I feel that is only right and the alternative, not saying anything and seeing misinformation spread or lack of information permeate, is wrong in the classroom. The students are the ultimate reason anyone enters the field of education. Seeing them suffer in any way is unacceptable.

\section{Purpose of the Study}

The purpose of this naturalistic inquiry project is to examine the perceptions of pre-service teachers as they learn and implement co-teaching strategies to enhance their understanding of inquiry-oriented teaching by using the science process skills. The issues involved in this project are numerous and varied depending on the connections the pre-service teachers make in both the university methods classroom and the future use in elementary school classrooms where they will be implementing these strategies.

The research questions that were used to determine if co-teaching enhances the understanding of teaching science process skills are:

- How do pre-service teachers develop an understanding of science process skills for scientific inquiry?

- How do pre-service teachers perceive the use of science process skills for scientific inquiry in the classroom?

- How do pre-service teachers develop an understanding of co-teaching strategies?

- How do pre-service teachers perceive co-teaching in the classroom? 
- How do science process skills instruction and co-teaching strategies impact preservice teachers' attitude towards learning and praxis?

\section{Significance of the study}

The reason this study is significant is because future curricula can be developed to expose pre-service teachers to the strategy of co-teaching and the content of science process skills to better equip the pre-service teachers for an elementary classroom. Hopefully, the results of this study will be reflected in future pre-service methods classes in the content taught and strategies used to teach that content. Ultimately the results will be seen in the elementary school classrooms of the pre-service teachers in the future. The perceptions from this study will show the frustrations of learning scientific inquiry and co-teaching, but will also show the feelings of success. If the specific frustrations can be identified, then perhaps more training could be done in the undergraduate methods classes to prepare the pre-service teachers to try new strategies.

The elementary students are the ones who will benefit most from this study by receiving an education that is based on scientific literacy and modeling of cooperative behavior.

\section{Definition of terms}

- Scientific Inquiry: a student-centered path starting at forming questions, going to determining evidence to collect, and then proposing, analyzing, and communicating explanations. Full inquiry is when the students take full responsibility for the experience, while guided is when the teacher assists the 
students with every step. Partial inquiry is a mix of full and guided and is determined by the needs of the students in the classroom.

- Basic science process skills: skills that provide a foundation for learning scientific inquiry

o Observing: using the five senses to gather information about an object or event

o Measuring: using standard guidelines (metric system or English system) to describe an exact dimension or using an estimate to determine the dimensions of an object or event

o Inferring: making a guess about an object or event based on observations

o Classifying: arranging objects or events based on certain indicators

o Predicting: stating the outcome of an event based on a pattern of evidence

o Communicating: using words, symbols, or graphs to describe objects or events (Padilla, 1990).

- Co-teaching: when two or more teachers are in the classroom sharing the responsibility for the planning, implementing, and reflecting on the lesson taught.

- Pre-service teachers: university undergraduate students in teacher education study generally in their third or fourth year who have not yet reached full time student teaching. These students have had a moderate amount of clinical experience in a public school classroom.

- Science methods class: a class taught by an instructor familiar with science instructional strategies and content to pre-service teachers in their third or fourth year of undergraduate teacher education study. 
- Classroom teachers: certified teachers in public schools of the surrounding counties of the university

- Instructor/Observer/Researcher: my position in the study. I will instruct the preservice methods class and collect and analyze the data.

\section{Assumptions and Limitations}

Overall assumptions and limitations are varied and were illuminated once the project was underway. One limitation was the motivation of the pre-service teachers to fully share the experience with me, the researcher and the instructor. There was a barrier that existed between the pre-service teachers and me, the instructor. I know that I was trying only to improve science education and not subject them to yet another project. However, I am not sure that they knew that throughout the study. My solution to this barrier was to know that I was going to have an effect on the participants, but try to place the data in the context of this knowledge. I did find that the pre-service teachers wanted to participate and wanted to implement these strategies expertly into an elementary classroom.

From this co-teaching that I did, my co-teaching partner and I felt more comfortable in the classroom and gained an enhanced understanding of how to teach. Through dialogue about the lessons previous to and afterwards, we exchanged ideas on how the lessons may best flow. During the lesson we both learned from each other and gained an understanding of how the instructional strategy fits the current lesson. We realized that perhaps another strategy would have worked better or the current one worked the best. 
In co-teaching, two or more professionals who would be co-teaching in a classroom could be me, a university faculty member; a pre-service teacher; and a supervising teacher from the public schools. This study does not delve into this particular triad, or even the pair of me and the pre-service teacher. This study focuses on the preservice teachers as they teach together. I was there as an instructor and observer of how they worked together to learn and then teach inquiry-oriented science lessons.

Logistically, I was limited by the number of pre-service teachers that were in the class. One elementary methods class was being used, and there are 24 students in this class-three male and 21 female. Also, I was limited by time. The classes met twice a week for an hour and 15 minutes for one full semester (16 weeks). Any follow-up would be difficult and cumbersome. I will not have an opportunity to follow up on their progress with science education in future clinical experiences to share in this study. 


\section{CHAPTER TWO}

\section{Review of Literature}

\section{Historical Context}

Around 1870 science emerged as a discipline to be taught in the early grades.

Since that emergence, science has been evolving and making its case to be a constant and strong member of the elementary school curriculum. It was not until 1957 with the launching of the Soviet Sputnik that science programs began to receive necessary funding to train the next generation of scientists. For the United States to be the most technologically advanced nation became a priority. Since then there have been a plethora of programs with acronyms that have tried to capture the essence of science education (Tolman \& Hardy, 1999). Just because these programs were founded does not necessarily mean that they have improved science education.

The goal of these programs is to keep teachers from putting science off until the end of the day or skipping it all together. It is also to keep the teacher from teaching science in the style of Friere's narration in which education is that act of "depositing, in which the students are the depositories and the teacher is the depositor" (Friere, 2000, p. 72). To prevent this, science should be taught to reach the following goals:

- Increase interest and appreciation for the world around us;

- Assist students in understanding basic scientific concepts;

- $\quad$ Teach students to use inquiry;

- Develop skills for problem solving;

- Increase scientific literacy;

- Show science, technology and society connections; and 
- Develop appropriate attitudes towards science (Tolman \& Hardy, pp. 6-7).

\section{Efforts to Improve Science Education}

Scientific literacy is one of the foremost goals of science education (AAAS, 1989; AAAS, 2000; NRC, 1996; Tolman \& Hardy, 1999). According to the NSES, every individual should be able to use scientific information to make choices in everyday life and be able to "learn, reason, think creatively, make decision, and solve problems" (1996, p. 1). The work began, though, with John Dewey in 1909 in his address to the American Association for the Advancement of Science (AAAS). Dewey said science teaching was relying too much on the information that is acquired rather than the process and state of mind. He posited the objectives of inquiry as formulating reasoning skills, developing a mindset for inquiry, and understanding science as a process. Bybee (2000) quotes Dewey as saying, "Only by taking a hand in the making of knowledge, by transferring guess and opinion into belief authorized by inquiry, does one ever get a knowledge of the method of knowing" (p. 26).

In the 1950s and 1960s, inquiry was termed enquiry by Joseph Schwab who preferred the learning to occur in the laboratory rather than the classroom. He proposed, among other aspects of enquiry, three levels of openness in the learning environment. The three levels involve materials that would lead students to discuss the investigations. The first level involved using laboratory materials to pose questions; the second level was to use textbooks or manuals; and the third level was to use actual experiences to lead students in a discussion of events. Schwab also proposed exposing the students to 
already-published reports and research and allowing them to offer alternate explanations and experiments.

Two projects have since emerged as vehicles to promote scientific literacy. The first is Project 2061 began by F. James Rutherford in 1985. Rutherford began work on inquiry in 1964 when he concluded that teachers need to understand the history and philosophy of science in order to properly teach inquiry. Rutherford refers to this in Science for All Americans, the publication of Project 2061, with a section on historical perspectives. Project 2061 is an initiative to outline what students should know by the time they reach twelfth grade. Science for All Americans was presented in 1989 outlining these recommendations. Benchmarks for Science Literacy was published in 1993 to expand on the goals presented previously (Bybee, 2000). The Atlas of Scientific Literacy was presented in 2001 as a graphic tool to see the connections among the benchmarks (AAAS, 2001).

The publication by the National Research Council, National Science Education Standards (NSES), in 1996 defines inquiry and the types of learning experiences students should have by grade twelve to achieve scientific literacy. According to Bybee, the NSES was brought about by a plea from the President of the National Science Teachers Association to develop national standards for science education. The report is a comprehensive look at achieving scientific literacy by all students and includes sections on professional development. The NSES stresses inquiry as the way to teach science (See Appendix A Science Teaching Standards and Appendix B Science Program Standards). Inquiry is not only content, but process according to the NSES. The standards are divided by what abilities the students should have in certain grades with inquiry and what 
understandings they also should have as a result of the inquiry process (Bybee, 2000). In 2000, an addendum was published to further address inquiry called Inquiry and the National Science Education Standards. In addition, state standards address inquiry as a requirement in science curricula (See Appendix C Science Content Standards and Objectives for West Virginia). All these endeavors can only enhance the future of science education for all individuals when studied and implemented into classrooms in public schools and universities.

\section{Translation to Pre-service Teachers}

The associations named previously have presented solid standards on what to expect from students in K-12 science classrooms (AAAS, 2001; NRC, 1996). However, according to a researcher from Texas Christian University, the teachers cannot present science in these ways if they have not been exposed to the science in this fashion (Kelly, 2000). Most pre-service elementary teachers take the usual load of arts and sciences, education theory classes, and methods courses. Kelly states that the experiences in their science courses in college are usually in the lecture mode with emphasis on facts not process. But this does not help the pre-service teacher to prepare to teach science in a classroom in accordance with the national standards. Barnett, Keating, Harwood, and Saam (2002) argue that if pre-service teachers can identify their own beliefs and attitudes about teaching science, then that in turn can lead to a more intensive view of teaching. The authors go on to ask how higher education faculty can help pre-service teachers learn to teach using an inquiry approach (Barnett, et al., 2002). 
The fear, as stated by Plourde and Alawiye (2003), is that elementary science education is deficient in producing teachers who will effectively teach science in an elementary classroom. Even John A. Craven, III states in a study on conceptions of the nature of science in pre-service elementary teachers that the efforts to improve science education have focused on those who already teach only science during the school day and have a background on science (2002). These fears stem from surveys by the National Science Foundation done in both 1993 and 2000. Plourde and Alawiye cite the survey results in a recent article in College Student Journal. Out of 6,000 teachers surveyed in elementary classrooms in grades 1 through 6 , the average time spent on science was 28 minutes for 1993 and 27 minutes in 2000. To compare, it was found that 52 minutes a day was spent on mathematics in 1993 and 60 minutes in 2000 while reading was 70 minutes in 1993 and 105 minutes in 2000 (Plourde \& Alawiye, 2003). Therefore it is imperative that all students have the opportunity to become scientifically literate (AAAS, 2001; Kelly, 2002; NRC, 1996; Plourde \& Alawiye) and preparing pre-service teachers is the first step.

Research Question One: How Do Pre-service Teachers Develop an Understanding of Science Process Skills for Scientific Inquiry?

What are the Science Process Skills?

According to Huppert, Lomask, and Lazarowitz (2002), science process skills are a "major goal of science education, since those skills are not only needed by scientists, but by every citizen in order to become a scientifically literate person" that can function in global society (p. 807). Huppert, et al. says that these skills are applicable to all 
elements of society and people should know how to use them in their daily life. The use of science process skills stimulates active learning which leads to higher levels of thought where students make decisions and solve problems. This decision-making and problem solving is scientific inquiry. The National of Academy of Sciences (1994) even refers to process skills as "scientific inquiry abilities" according to Harlen (1999, p. 129).

Science process skills is the commonly used term now, but scientific method, scientific thinking, and critical thinking have all been synonymous with these skills at one time or another. It was with the Science-A Process Approach (SAPA) project that these terms became widely known. The skills are not just used in one realm of science, but all the disciplines and represent the way a scientist solves a problem (Padilla, 1990).

The skills are: observing, measuring, inferring, classifying, predicting, and communicating. Observing is when students use their five senses to gather information about an object or event. Measuring is using a standard or nonstandard system to exactly determine the dimensions or estimate the dimensions of an object or event. Inferring is when students will make a guess or assumption on an object or event based on observation. Classifying is when students will order or arrange objects or events into categories and be able to defend their categorization indicators. Predicting is when the students will determine the outcome of an event based on a pattern of evidence previously gathered. Lastly, communicating is putting the information into words, symbols, or graphs to describe the object or event (Padilla, 1990). 


\section{Importance of Science Process Skills}

Paul Arena (1996) writes in Australian Science Teachers Journal, "The development of higher order process skills in science seems best achieved by an openinquiry style" (p. 34). He cites a study done by Roth and Roychoudhury (1993) that found students successfully used science process skills in solving an open-inquiry problem. The study concluded that the process skills are learned in the context of inquiry and will mean more to the students. Arena claims that open-inquiry and process skills should be an increasingly larger part of science education because they help the students stay engaged in learning.

Harlen (1999) repeats this claim by saying that these skills increase scientific literacy by allowing students to identify questions and draw conclusions to make decisions about natural phenomena. Studies have shown that students' knowledge of process skills increased their problem-solving skills (Akkus, Kadayifci, Atasoy, \& Geban, 2003; Alparslan, Tekkaya, \& Geban, 2003; Chang \& Weng, 2002; Huppert, Lomask, \& Lazarowitz, 2002). The studies mentioned above are from chemistry, biology, computer science, and earth science classrooms. All used process skills to show student achievement in problem solving. All studies showed process skills to be beneficial in the classroom.

Harlen (1999) continues to posit the importance of process skills by relating the learning of science to the learning of process skills. Harlen says that the ability to make predictions, pose questions, collect data, and then test the prediction is learning science. The students then become able to take these ideas they have formed and translate them into larger ideas with more complicated explanations. The learning of process skills is 
very important to science education, for without it the students are unable to make necessary connections and may not be able to understand the world around them (1999).

\section{Assessing the Science Process Skills}

Process skills should be assessed in the context that is developmentally appropriate to the student. The students should have ample access to materials and also have the necessary background knowledge of the concept studied to accurately learn the process skill. All the process skills must be taught in relation to some type of content (Harlen, 1999).

Harlen (1999) leads the research on how to assess students on the understanding of process skills. The information that gives teachers the opportunity to judge the effectiveness of the use of process skills can be grouped into four categories. These categories are the basis for the observation instrument used in my study. The categories are: observing the students, questioning the students, assigning tasks, and asking the students to communicate their findings.

Harlen (1999) describes the first category, observing the students, as listening and responding to the students to gain an understanding of their reasoning. The second category is using questions to invite students to explore more questions and making sure open-ended questions are used. The third category is dependent on the process skill where the teacher will evaluate the components of the skill performed by the students. Lastly, the fourth category is the communication of the students' work. The students will not only have a product at the end of the lesson, but will be able to discuss that product. 
Research Question Two: How do Pre-Service Teachers Perceive the use of Science Process Skills to Implement Scientific Inquiry in the Classroom?

Importance of Scientific Inquiry

In the Call to Action for the National Science Education Standards, Richard Klausner and Bruce Alberts (1996) say, "An understanding of science makes it possible for everyone to share in the richness and excitement of comprehending the natural world" (p. ix). Therefore scientific literacy is going to help everyone when making decisions and discussing issues in our society. In addition, skills such as problem solving, critical thinking, and cooperative learning will be honed as a result of having a solid background in science; a background that is built by many individuals including science educators by using inquiry-based strategies (NRC, 1996). Therefore, scientific inquiry is the vehicle to using process skills to teach students science.

Science process skills are the means to learn scientific inquiry and to increase scientific literacy. Harlen (1999) uses a definition of scientific literacy from the Organization for Economic Co-operation and Development from 1998 as, "being able to use scientific knowledge to identify questions and to draw evidence-based conclusions...to make decisions about the natural world" (p. 130).

Paul Arena (1996) writes, “An open inquiry style of instruction appears best suited to stimulating the learning of process skills because they allow students to pursue problems of genuine relevance" (1996, p. 34). In the Journal of Research in Science Teaching, Pizzini, Shepardson, and Abell (1991) identified open or full inquiry as a strategy that allows the student to question the problem and then devise investigations to solve the problem. This type requires the students to use scientific concepts and 
principles and also higher order thinking skills which are also known as science process skills (Martin-Hansen, 2002; Pizzini et al., 1991). Arena goes on to postulate that if students, particularly in the primary grades, are allowed to take ownership of their learning, then there is a deeper understanding of science. This remains true even for older students. For example, Cothron, Giese, and Rezba (1993) say that when students do not experience the "wonder" of science and discovering, then they will be less likely to enter high school science courses and eventually pursue science in a career (p. vii). To this end, College Pathways to the Science Education Standards postulates that preservice courses and the pre-service teachers in these courses will determine the interest, knowledge and comfort of science for school-aged children (2001).

The importance of scientific inquiry is clear, but for those that need evidence, the National Research Council sponsored the Committee on Development of an Addendum to the NSES on Scientific Inquiry in 2000. In this addendum, chapter six outlines the case for inquiry. In this outline, the science process skills permeate. The investigative skills and problem-solving skills are obvious in each finding of this addendum, therefore verifying the link of science process skills to scientific inquiry.

This evidence includes a 1999 report called How People Learn in which the National Research Council found six general trends on learning science. The first is that understanding science is not merely knowing facts. Students should be able to do the following scientific thinking, or inquiry, when faced with a problem:

- fully describe the problem, but not try to solve it immediately,

- decide which information is important and should be regarded when analyzing the problem, 
- determine how they will fully analyze the problem (NRC, 2000).

Inquiry involves "reasoning, careful observing, and logical analysis" (NRC, 2000, p. 116).

The second and third findings generalize on students' knowledge base and integrate inquiry thinking. The second finding is students will construct knowledge based on what they have already learned or believed, even if it is wrongly learned. The third is students will develop their knowledge by revisiting their current ideas and add new ones to what they already have learned. Even if they have learned something incorrectly, there is the chance that the students will find these implausible and change their concepts. According to the research in How People Learn, this often happens in inquiry situations when students are gathering evidence and exhibiting solid reasoning skills in other words, using science process skills.

The fourth finding addresses the environment in which students learn. It was found that students who interact with each other benefit from each other. Later the report, How People Learn, discusses a community-centered environment. This finding relates directly to that idea. The students, who challenge each others' ideas, encourage each other and allow each other to search for deeper meanings, benefit greater than those who learn alone. The students' knowledge is constructed based on a community of sharing of ideas and is therefore solidified. The students then can take a proactive role in defending their ideas.

Findings five and six relate to the acquisition of control of the learning. Finding five says in no uncertain terms that students must take ownership in their learning. They need to be able to know when to ask questions and what questions to ask. They should 
be able to articulate what they know and what they want to know, and therefore are aware of what they need to solve the problem. In an inquiry setting, the student would need to know what evidence is present, what evidence needs to be gathered and what ways that evidence will be gathered. Finding six states that once the learning is controlled it can be transferred to other learning situations. Without knowing what has been learned, transference is difficult. The students can apply what they have learned in new settings and learn to a deeper degree. For problems to be solved in an inquiry fashion, these findings must be addressed (NRC, 2000).

It is with the science process skills that these findings are found to be important in science instruction. Arena's (1996) concept of ownership of the learning is most relevant in scientific inquiry. In an open-inquiry setting, students are able to investigate problems that are important to them and to take control of their learning.

Inquiry-based teaching can vary and variations are acceptable, as long as the experiences are centered on scientific questions and the students are fully engaged in critical thinking. Sometimes the students are not completely prepared for a full inquiry lesson and certain skills, the science process skills, must be taught to prepare them. A list of these skills for grades one through four is provided in the NSES. They are as follows, taken directly from the publication:

- Ask a question about objects, organisms, and events in the environment;

- Plan and conduct a simple investigation;

- Employ simple equipment and tools to gather data and extend their senses;

- Use data to construct a reasonable explanation; and

- Communicate investigations and explanations (NRC, 2000, pp. 161-162). 
These skills relate directly to the six process skills used in this study: observing, measuring, inferring, classifying, predicting, and communicating. Again, it is obvious that scientific inquiry is learned from using the science process skills, even to say that, "the essence of science is validation by observation" (AAAS online, 1989).

\section{Myths and perceptions of inquiry}

There are several myths that should be addressed when studying inquiry. Some teachers say that inquiry is not supported by the administration. In a recent study Haney, Czerniak, and Lumpe (2003) found that the perceptions varied among administrators, teachers, students, and parents in an effective science learning environment involving constructivist learning which included elements of inquiry. It was found that the most positive perception was from administrators with teachers and then students following. Parents were the least positive about science classrooms being an arena for higher order thinking skills. The authors reveal that sometimes the teachers only perceive that they do not have administrative support (Haney, et al.).

Another myth is that pre-service teachers do not think in-service teachers actually use this strategy. However, a study was recently completed with pre-service and inservice teachers who participated in a web-based forum discussing inquiry-based approaches. The pre-service teachers would watch the in-service teachers on video and along with the in-service teachers' materials and student work would discuss the elements of the inquiry-based lessons. It was found that 26 out of 28 pre-service teachers found this forum useful in forming their own idea of what inquiry is and how they can use it in their own classrooms. It was also found that the pre-service teachers felt more 
comfortable attempting innovative teaching methods, thereby giving them confidence to participate in new teaching strategies in their career (Barnett, et al., 2002).

It is also thought that students, specifically pre-service teachers in science methods classes, do not gain knowledge when inquiry-oriented strategies are used. Janet Kelly (2000) found that when restructuring her science methods class to use more inquiry-oriented strategies, her pre-service teachers averaged a $40 \%$ on the pre-test involving light and another on microorganisms. At the end of the new methods course the pre-service teachers averaged $80 \%$ on each post-test. Even $96 \%$ of the pre-service teachers developed units that met Kelly's requirements of inquiry-based at the end of the course. Kelly did find in a follow-up that these pre-service teachers who showed these marked improvements felt they did not have enough time to teach science the way it should be taught.

Research Question Three: How Do Pre-Service Teachers Develop an Understanding of Co-Teaching Strategies?

\section{Emergence of Co-Teaching}

Research has shown that co-teaching leads to enhanced learning by the participants (Austin, 2001; Eick et al., 2003; Harris \& Harvey, 2000; Kirkwood-Tucker \& Bleicher, 2003; Lonning \& DeFranco, 1994; Roth \& Tobin, 2001; Thomas \& McRobbie, 2002; Vaughn, Schumm, \& Arquelles, 1997). Co-teaching began as a tool used by special educators in accordance with meeting the needs of disabled students. Teachers following Section 504 of the 1973 Rehabilitation Act use co-teaching to make sure the needs are met of their students and employ inclusion in a collaborative classroom (Gately 
\& Gately, 2001). Co-teaching has surfaced in the United States and Canada with studies by Wolff-Michael Roth and Kenneth Tobin in public schools to enhance the learning of the students and teachers (Roth, 1998; Roth \& Tobin, 2001). Co-teaching has also emerged in universities with a clinical experiences handbook being written to explain coteaching techniques to its clinical students (Co-Teaching). Finally, co-teaching is also found in the university-level classroom, specifically a science methods class where the students learn co-teaching and then work with experienced teachers in the public schools (Eick, et al., 2003).

\section{Defining co-teaching}

"Co-teaching is a bit like a marriage. Both partners have to feel that they are giving $100 \%$ and have to want things to work out" (Vaughn, et. al, p. 2, 1997). With that, there are some tenets that define co-teaching. Cook and Friend (1995) identify four main components that define co-teaching. The first is the presence of two or more educators. For special education, this may mean that there is a general education teacher and a special education teacher in an included classroom. This can also mean two or more educators with varying expertise addressing the same classroom of students. The second component of the co-teaching definition is these educators deliver instruction. They cannot merely be observers for a study hall situation or monitoring a guest speaker. There must be a substantial amount of instruction taking place in the classroom led by these educators. The third component is the educators must teach a diverse group of students. This means the students vary in ability or otherwise, but can mean regular education and special education. It is this component that allows co-teaching to reach 
students with differing ability levels. The last component involves the physical arrangement. The teaching must occur in the same physical space or classroom. Some groups may step just outside the door for reduction of noise level, but the cohesion of the whole group cannot be lost (Cook \& Friend).

How does one know co-teaching is occurring?

Cook and Friend (1995) and Co-Teaching, handbook from James Madison University, offer a general idea about what co-teaching will look like in a classroom. There are five general approaches to co-teaching.

- One teach, one support

- Parallel teaching

- Alternative teaching

- Station teaching

- Team teaching (Cook \& Friend; Co-Teaching)

As with any teaching strategy, there are advantages and disadvantages to each of these co-teaching approaches. There are also variations of these approaches. The key is for the co-teaching team to find what best fits the needs of that classroom.

In the first approach to co-teaching, one teacher has the primary responsibility of planning the lesson and teaching the lesson. The other teacher will circulate about the room and assist students with the lesson (Co-Teaching). Some may call this "grazing" where the other teacher will graze around the classroom offering academic assistance or even behavioral assistance (Vaughn, et al., p. 4, 1997). The advantages to this type include increased student assistance, better classroom control of off-task behaviors, 
minimal loss of time distributing materials, and opportunities for the teachers to learn from each others' instructional methods. The disadvantages are decreased authority in one teacher through perception of the student, possible distractions caused by teacher circulating, and expectations from the students to receive immediate attention (CoTeaching). In order to combat the decreased authority of one teacher from the students' perspective, Wunder and Lindsey (1997) suggest rotating the roles of each teacher.

The second approach, parallel teaching, allows both teachers to be authority figures in half of the class. This approach calls for the teachers to split the class in half and each teacher to instruct his/her portion simultaneously on the same lesson. The lessons are identical, but the groups are smaller. The advantages, including smaller groups, are planning with another teacher and allowance of some students to be separated if necessary. The disadvantages are the lessons must be timed precisely to finish at the same time, the groups must be separated enough as not to distract from the other, and both teachers will have to be equally competent in the particular lesson (Co-Teaching). Wunder and Lindsey (1997) suggest that this technique be used for hands-on activities that are mostly student-paced.

Alternative teaching is the third approach to co-teaching. In this arrangement, one teacher will remove a small group from the whole group setting and work with this group for assessment, remediation, enrichment, or a special project. The removal can be either in the classroom or outside of the classroom. The advantage for this is to meet the needs of the students in the small group on a personal level. The disadvantages of this method may include a fear of labeling groups according to which teacher works with them, confusion with changing authority between teachers, and an uncertainty of the physical 
arrangement of the groups within the classroom (Co-Teaching). Wunder and Lindsey (1997) suggest that all students be placed in this small group at some time and be allowed to work separate from the whole class.

The fourth approach to co-teaching is called station teaching. There should be at least two or three separate stations or learning centers in the classroom and the students are to circulate through these stations independently or under the guidance of a student leader or instructional aide. Each teacher takes one station and presents a lesson at that particular station. For example for three stations, each teacher is present at one and then the third is for students to work through independently or with the assistance of a parent or aide. The advantages to this approach are giving each teacher full responsibility for his/her station, working students in small groups, covering more material in less time, engaging students so there is less off-task behavior, and maximizing the use of volunteers in the classroom. The disadvantages are the amount of preplanning, preparation of all materials, enduring the noise level, pacing the stations, and allowing the students to work independently at one of the stations (Co-Teaching).

The final approach is the one used in the studies by Roth and Tobin and is called team teaching. Both (or all) teachers assume shared responsibilities for all aspects of instruction in the classroom. The instructional method is mostly discussion, not lecture, and students are encouraged to discuss with the teachers. This approach can work well when student teachers are present or when university-level personnel are present in the classroom. The advantages are the active roles of each participant, all teachers are viewed as equal, and it may promote risk-taking in the classroom to try new strategies that would not be attempted alone. The disadvantages are the amount of planning 
involved and the difficulty with clearly defining the roles of each participant (CoTeaching). Wunder and Lindsey (1997) say that this allows the teachers to blend their styles as well as their individual expertise.

\section{Heuristics of Co-Teaching from the Roth and Tobin Studies}

In the fall 2003 issue of New Directions for Teaching and Learning, Charles F. Abel discusses his model for the use of heuristics to solve problems. It is appropriate to use heuristics in a study using problem-solving as well. Heuristics, according to Abel, are "experimentally derived cognitive" guidelines in problem solving (2003, p. 53). He further says that heuristics help in simplifying choices in the problems and understanding the complex factors that affect the problem.

Wolff-Michael Roth and Kenneth Tobin have led the research on co-teaching in mainstreamed classrooms (see Roth, 1997; Roth \& Tobin, 2001, Roth \& Tobin, 2002). They have participated in and directed studies involving pre-service teachers, practicing teachers, and university personnel in public school settings. They present in their research an epistemology of teaching that transcends current thought. They focus on the camaraderie of teachers and the benefits of having more than one teaching professional in the classroom. Roth and Tobin's At the Elbow of Another (2002), a study of co-teaching done in an urban school, lists heuristics gathered from their study. The heuristics listed below illustrate the key concepts of co-teaching seen in the Roth and Tobin study.

- Co-Planning

- Respect

- Rapport 
- Creating Space

- Seamlessness

- Reciprocal Coparticipation

- Complementarity of Action (p. 189).

Research Question Four: How Do Pre-Service Teachers Perceive Co-Teaching in the Classroom?

Considerations with Co-teaching

Co-teaching is found on a large scale in the literature in special education classes where inclusion is employed to immerse students with disabilities with students without disabilities (Cook \& Friend, 1995; Gately \& Gately, 2001; Sterling \& Goor, 1998;

Vaughn et. al, 1997; Weiss \& Lloyd, 2002; Wunder \& Lindsey, 1997). It is important to note some considerations when co-teaching in an environment either with or without students with disabilities. The considerations for the included classes are also relevant for the ones of regular education (Cook \& Friend). First of all it is necessary to examine the rationale for co-teaching to see what the benefits can be in a classroom. Next, the components of co-teaching can be investigated to see what problems may or may not arise. Lastly, there are three levels to co-teaching that naturally occur when co-teaching is being employed. It is imperative to know these levels and know which level is being represented in a classroom.

Cook and Friend (1995) identify the rationale for co-teaching: to enhance the learning opportunities for students. "Any discussion of reasons for co-teaching should begin with an understanding of the potential benefits to students" (Cook \& Friend). The 
instructional methods vary and students have more opportunities to succeed in the classroom (Cook \& Friend). Other reasons include those cited by Gately and Gately (2001). Teachers participating in a collaborative setting express feelings of "worth, renewal, partnership, and creativity" (Gately \& Gately, p. 41). Further research is presented in specific studies that enhance these feelings.

Problems invariably arise in any situation with more than one person making decisions. Cook and Friend (1995) have identified some topics and questions that pertain to decisions that must be made to create a collaborative working environment. The first topic is instructional beliefs, and the questions involve each teacher's philosophies and beliefs about the role of teachers in the classroom. The co-teachers must address their beliefs and determine how these beliefs will be translated in the classroom. The second topic is planning. The co-teachers need to meet for a minimum of half an hour, learn how to divide up tasks, and decide how much joint planning is really necessary. Vaughn et al. (1997) devised a co-teaching daily lesson plan guide that asks specific questions relating to the individual duties of the co-teachers to use when planning. The questions are as follows:

- What are you going to teach;

- Which co-teaching technique will you use;

- What are the specific tasks of both teachers;

- What materials are needed;

- How will you evaluate learning; and

- Information about students who need follow-up work (Vaughn et. al, p. 6) 
The next consideration is the establishment of authority in the classroom by the coteachers. The co-teachers will need to decide how they will convey that both teachers are the authority and decide how they will enforce that with the students. The fourth topic is confidentiality, not only about the co-teachers, but the students as well. The teachers will decide how much of their teaching they will share and how much they will not. They will also need to determine what information about the students will be shared if one teacher should know more than the other. Noise level and discipline are some other topics that should be addressed. The questions in these topics include how much noise is tolerable, what behaviors are acceptable and unacceptable, when one teacher will intervene, and whether there will be rewards or consequences. Along with classroom management, the teachers will need to decide the instructional routines and organizational routines of the classroom. Lastly is assessment: of the students and of the teachers. The teachers will need to decide how to give feedback to each other and how to assess the students collaboratively (Cook \& Friend, 1995).

Finally in consideration of co-teaching, there are three levels that occur naturally in the developmental process as outlined by Gately and Gately (1997). The first stage is the beginning stage. In this stage the conversations are mostly superficial as each teacher establishes his/her boundaries with a colleague they may only know on a personal level. It is difficult to cross the line to professional relationship and there may be uneasiness and detachment for the most part. Sometimes teachers stay at this level and give up on co-teaching. The second stage is compromising. The communication becomes clearer, more open and interactive. Each teacher takes an even more active role than before and begins to compromise on a variety of issues that lead to trust. The last stage is 
collaborative. There are teachers that take as much as two years to reach this stage. The communication is completely open and interactive and there is a sense of mutual admiration and respect for each other. There is a high level of comfort and ease that is evident by all-students, teachers, administrators, and parents (Gately \& Gately, 1997). It is imperative that all these considerations be explored in order to fully understand coteaching.

\section{Perceptions of Co-teaching}

In order to fully explore the perceptions of co-teaching, it is necessary to see what the teachers in the inclusive classes think of co-teaching with a special education teacher. With these perceptions, some general trends and issues can be seen that will assist research (Austin, 2001). The following studies show the perceptions of teachers in inclusive classrooms, teachers in regular education classrooms, and pre-service teachers in classrooms. These issues presented are legitimate and shed light on the topic of coteaching. These studies show there are frustrations and pressures that exist in this method of teaching as well as positive aspects of co-teaching.

Special Education. In inclusive classrooms, special educators are teamed with general education teachers, and the roles of each teacher vary. In both the Austin (2001) and Weiss and Lloyd (2002) study, the special education teachers agreed that most of their time was spent circulating among the students offering instructional assistance. The general education teacher did most of the instruction in these classrooms. One teacher says, "What I do is just go in and help out with whatever they are doing and do the stuff I can," (Weiss \& Lloyd, 2002). 
The problem, according to both studies, is the content. In secondary classes, the general education teacher is the content expert. Special educators may be able to assist with some content, but as this same teacher asked, "Do you think I would have the audacity to go in to the geometry class and say I was a collaborative teacher?" (Weiss \& Lloyd, 2002). Even with these feelings, the teachers in both studies feel co-teaching is worthwhile (Austin, 2001; Weiss \& Lloyd, 2002).

Another issue with co-teaching is the support from the administration. Even though the administrators agree that co-teaching can be successful, little time is allowed for co-planning. The teachers agree that co-planning is crucial to the success of a coteaching classroom. Furthermore, there is pressure from the administration and the community to keep co-teaching in the classrooms because administrators have seen how successful it can be with elementary schools as examples (Austin, 2001; Weiss \& Lloyd, 2002).

Pressure is further applied because of the diploma that is awarded. The Austin (2001) study implies that the reduced ratio of teacher and student allows for more individual attention and more opportunities for learning. The teachers in the Weiss and Lloyd (2002) study were even asked by the administration to include as much regular education exposure as possible in the Individualized Education Plan (IEP). The teachers say that the students will not receive a regular education diploma if there is not a sufficient amount of regular education. The problem with this scenario is that the teachers, therefore, feel pressured to co-teach and sometimes that is not the optimal situation. 
General Education and Pre-service Education. Co-teaching has been studied in regular or general education classes as well where there are no pre-determined special education students (Roth, 1997; Roth \& Tobin, 2001, Thomas \& McRobbie, 2002). These studies focused on basically the same elements of teacher perceptions and student perceptions of co-teaching. In all studies there was a positive perception of co-teaching after the projects were completed. All studies also tout increased teacher knowledge, increased feelings of professionalism, and increased opportunities for students to succeed in the classroom (Roth \& Tobin; Roth; Thomas \& McRobbie).

In the Thomas and McRobbie study (2002), a practicing teacher is paired with a team of university professors specializing in science education which is similar to the Roth (1997) study where a university professor is paired with a practicing teacher. This is somewhat like the Roth and Tobin (2001) study where a team of university personnel, a pre-service teacher, and practicing teacher engage in classroom instruction and dialogue during an instructional unit. It is clear from all studies that the focus was "teacher as learner" (Thomas \& McRobbie, p. 407) and the secondary impact was the instructional opportunities for the students (Roth, Roth \& Tobin, Thomas \& McRobbie,). The teachers in these studies all assumed responsibility for the instruction of the students in science. It is this premise that is the thrust of my study. These studies all showed that the teachers learned how to teach science in a different way, either constructively or using social learning. The teachers all expressed an increased understanding of the instructional techniques while they may have had problems implementing them. The end result is the same for all studies: the teachers learned how to teach science in an effective way (Roth, 
Roth \& Tobin, Thomas \& McRobbie;). The teachers also learned to communicate more effectively with their peers (Roth, Roth \& Tobin, Thomas \& McRobbie).

In the Roth studies $(1997,2001)$ and in an article co-written with Kenneth Tobin (2001) about the 2001 study, the main reason identified for the increased teacher learning was the dialoguing, termed "co-teaching/co-generative dialogue" (Roth \& Tobin, 2001, p. 253). Roth and Tobin (2001) say learning is the first goal of co-teaching where teachers work "at each other's elbow" to take responsibility for the instruction (Roth \& Tobin, p. 15). It is with this close proximity that the teachers are able to meet and discuss the events in the classroom during the co-teaching instruction. This discussion, or cogenerative dialogue, provides everyone an equal chance to participate in the discussion and be an equal partner in the instruction. Roth and Tobin go on to discuss the importance of equal standing by all participants sometimes even including students in the dialogues. The researchers go on to list elements indicating a successful dialoguing session. These are taken from the Roth and Tobin article.

- Respect,

- Rapport,

- Inclusion of stakeholders,

- Variety of ways to participate,

- Variety of opportunities to participate, and

- Variety of discussion topics (p. 17)

The researchers list many ways and opportunities to participate and even suggest the discussion topics. The point is clear, though, that, all participants will be engaged in the lesson at all times and no one can be a "fly-on-the-wall" (Roth \& Tobin, p. 17). In 
summary, all studies showed the impact of co-teaching and make suggestions for future study. It is with these impacts and implications that this project will look at the perceptions of the pre-service teachers as they co-teach to see if they have an increased understanding of inquiry-oriented strategies.

Research Question Five: How do inquiry-oriented and co-teaching strategies impact pre-service teachers' attitudes towards learning and praxis?

\section{Gap between theory and practice}

There exists in public education a gap between the theory learned at the university level and the actual practice of teaching. This gap can be the result of a commitment to increase academic skills necessary in college or the workplace or the result of adherence to state-mandated curriculum standards (Kagan, 1993; Morrison \& Marshall, 2003). When Dona Kagan, a professor of education at George Mason University, interviewed two teachers from a local school she discovered that the teachers' performance in the classroom was centered on adhering to the acquisition of information for standardized tests. Interestingly enough, ten years later in a study by Morrison and Marshall, two professors at the University of Texas-Tyler, the same was found to be true. Morrison and Marshall also found that the teachers wanted to bypass best practices so as to keep the class well managed. One pre-service teacher observed, "my mentor teacher has a reason for why every area in the room is closed" (Morrison \& Marshall, p. 293). The sad part is this was a kindergarten classroom (Morrison \& Marshall).

The university professors in these studies focus on the culture of the pedagogical methods. They know that the best learning environment for the students is a constructivist and student-centered one. They strive to teach best practices that engage 
the interests of the children in the classroom. Further, they try to find placements in public school classrooms that meet these pedagogical goals. It is important for the university to try to work with the public schools to bridge the gap between what is taught at the university level and what is happening at the public school level. Morrison and Marshall (2003) suggest that in the short term, methods teachers at the university level find classes that closely identify with what the university is teaching. In the long term, they suggest collaboration with the public schools to keep the teachers informed of the best practices (Morrison \& Marshall).

Roth and Tobin (2001), in their co-teaching study set in Philadelphia, PA, introduced a term called praxeology deemed to show the insight gathered from professionals dialoguing about their experiences in teaching. The term praxis, then, has become known as the word for actual teaching. The professionals all were in the same classroom co-teaching the same students, but each had a unique perspective. It is through the dialogue that the professionals have practiced praxeology which has allowed them to gain understanding of the same lived experience. It is through this praxeology that the professionals can analyze the experiences critically and frame their study.

Roth and Tobin (2001) use phenomenology also in their study to show the learning and coming to know that is gained from praxis. They say that to truly understand praxis, the participants must experience being-in, being-with and habitus. Habitus, according to Roth and Tobin, is the notion of knowing what the structure of a situation is by being immersed in the situation. Habitus cannot occur unless there is a being-in and a being-with participants who know the situation. For example, Kenneth Tobin assumed the role of a chemistry teacher in an urban school, but he could not reach 
habitus until he had been with and been in the situation to understand its regularities and irregularities. He, as well, as other teachers, found that teaching is not static. There are interactions that change the climate of the classroom.

Tobin also found out that teaching in an inner city school was not going to be the way he learned to teach. "Science as I knew it, and had experienced it in schools, did not seem to have place at this time for these students" (Roth \& Tobin, 2001, p. 69). He found that is was difficult to gain the students' respect and it was difficult just to teach science. In a sense, he had to re-learn how to teach science to inner-city students. It was through his co-teaching with other teachers and Roth, a fellow educational researcher, that he was able to dialogue and critically examine his experience to make it better for him and the students. All in all, Tobin concludes that the best way to learn to teach is to get out into a classroom and actually do it (Roth \& Tobin). It is this realization that is crucial to my project. The perceptions of the pre-service teachers will be recorded and studied to see if they have a changed outlook on learning and praxis after completing the inquiry and coteaching project.

Perceptions on learning co-teaching and praxis in the actual classroom

Eick, et al. (2003) found that pre-service teachers who have engaged in assistance with laboratories and handling materials in public school classrooms often say there is a disconnect between what the university is teaching and what is actually happening in the classroom. The pre-service teachers offer some advice to the university to fix this according to the study and also according to my personal experience in higher education, the advice is: more and earlier field experience work. Eick et al. questioned the 
experiences though and sought to find out if co-teaching would help in preparing these students. The researchers paired pre-service teachers and practicing teachers in a coteaching format. The pre-service teachers taught with the practicing teacher, but taught the practicing teacher's lesson. The pre-service teacher was not responsible for planning the lesson, merely implementing it in keeping with inquiry-oriented strategies. The focus was modeling the practicing teacher's behaviors and lessons. The pre-service teachers and practicing teachers did engage in extensive dialogue prior to and after the lessons. The study yielded four positive outcomes that directly show the pre-service teachers' perceptions of learning and praxis in a classroom of co-teaching while practicing inquiry. The outcomes are:

- A feeling of comfort when learning to teach;

- The opportunity for critical reflection when modeling the teacher's lesson;

- A development of confidence in teaching and in managing student behavior; and

- The opportunity to see that inquiry can be done well in a classroom (Eick et al., 2003).

The authors go on to say with these positive outcomes, inquiry will most likely be used later by these pre-service and practicing teachers (Eick et al.).

\section{Summary}

The use of inquiry-oriented strategies and co-teaching techniques is not new, according to the literature, but is not fully developed. Only since 1996 with the NSES has there been a national move to include inquiry-oriented strategies into the classroom. 
Even so, the NSES published an addendum in 2000 to further illustrate inquiry and promote its use and present a full image if what inquiry is. The AAAS promotes inquiry as well in its publications and has made several contributions to the literature on the use and effectiveness of inquiry. With the publication of Inquiring into Inquiry Learning and Teaching in Science, the AAAS gave teachers snapshots of what the experts believe about inquiry and about how inquiry can be done in the classroom. The inquiry web from the AAAS, and the features of inquiry from NSES have captured the essence of inquiry for classroom teachers as well as curriculum developers and university personnel. Teachers are certainly not lacking in the definition of inquiry and ways to use it in their classrooms. There may be a lack of studies, though, that show the ease and effectiveness of inquiry.

Co-teaching has less literature and studies available to show its effectiveness. There are studies of co-teaching in special education classes where co-teaching first blossomed. Even with the few studies of co-teaching in regular education classes, it is hard to grasp the complete picture of co-teaching in several situations. Drs. Roth and Tobin have contributed a great deal to the literature on co-teaching, especially in a science classroom, but these should not be the only studies available. Co-teaching has been studied enough to be defined and seen as a tool of teaching that could be positive in any classroom. There are many ways to co-teach, but the one studied the most is merely having more than one professional in the classroom responsible for the instruction of the students.

With co-teaching and inquiry being studied in a very few cases, it is important to note that this may not represent all classrooms. University students in teacher education 
know that there is a difference between what occurs in the university classroom and what occurs in the public school classroom. This gap should be examined and the university students should not be afraid to try the techniques learned in the university even if the public school teacher may not understand the technique or think the technique will work with his/her students. Hopefully, with the attempt to close this gap with bringing in ideas from the university, teachers may dialogue more and feel more like professionals in their schools. They will be part of a group that interacts and discusses instructional techniques in addition to classroom management. The focus will become the education of the students not solely the management of them. 


\section{CHAPTER THREE}

\section{Methods}

\section{The Participants}

There was no random sampling of participants because the study requires the participants to be in an elementary science methods class. There was randomness in the particular section of the class selected. An early afternoon class was selected because of my schedule during this particular semester. The participants in this section, therefore, had no knowledge of this study until the first day of their methods class. The elementary science methods class is a required class in the professional preparation program at a medium-sized state university. The class used in this study consisted of 24 pre-service students -21 female and 3 male.

The following charts describe the participants more vividly with respect to age, gender, and preparation level. Table A shows the different age levels of the participants. Age is divided into three groups - early 20 s, late 20 s, and 30 or more years of age. Table B shows the varying levels of preparation of the participation by how far they are away from the final semester of their program of study, also known as student teaching. Student teaching is when the participants are placed in a public school for the entire school day over the course of a semester. They are required to assume the same duties as the classroom teacher during this time period in order to be certified by the state for licensure to teach. Levels of preparation are divided into three groups also-within one semester before full-time student teaching, within two semesters (one year) of student 
teaching, and more than a year from student teaching. Table $\mathrm{C}$ shows the difference in gender of the participants.

Table A

Age Groups of the Participants

\begin{tabular}{|l|l|}
\hline \multicolumn{1}{|c|}{ Age level } & Number of students within the level \\
\hline $21-25$ years of age & 21 \\
\hline $26-29$ years of age & 1 \\
\hline 30 or more years of age & 2 \\
\hline
\end{tabular}

\section{Table B}

Preparation Level of the Participants

\begin{tabular}{|l|l|}
\hline Preparation level & Number of students within the level \\
\hline One semester prior to student teaching & 5 \\
\hline Two semesters prior to student teaching & 5 \\
\hline More than a year prior to student teaching & 14 \\
\hline
\end{tabular}

Table C

Gender of Participants

\begin{tabular}{|l|l|}
\hline Gender & Number in the group \\
\hline Male & 3 \\
\hline Female & 21 \\
\hline
\end{tabular}

Procedures 
In this study, I assessed the pre-service teachers' understanding and perceptions of the following process skills:

- Observing

- Measuring

- Inferring

- Classifying

- Predicting

- Communicating

I also assessed the understanding and perceptions of co-teaching as modeled by me and a colleague in higher education. The co-teacher and I presented a series of lessons that covered the above-listed science process skills. The lessons used in this study were adapted from Gabel's (1984) Introductory Science Skills in which the skills were placed in a scientifically appropriate environment such as physics or chemistry.

The co-teacher and I modeled co-teaching as defined by Roth and Tobin (2001) where both teachers are responsible for the flow of instruction in the classroom.

The pre-service teachers were asked to submit reflective journals after each lesson individually. After two of the process skills were presented by the co-teachers, the preservice teachers were asked to choose a co-teaching partner and teach a lesson covering one of those process skills to the class. In total for the semester, the pre-service teachers taught three lessons to the class. The pre-service teachers were also asked to agree to an interview at the end of the semester.

On the first day of class a consent form was offered for review by the participants (See Appendix E Consent and Information Form). No penalty was assigned if the 
participants did not want their work used in the study. Reflective journals and lesson plans are part of the normal assignments for the class, but interviews are not. The participants were asked to allow me to use their reflective journals and lesson plans for the study and then, later, sit for an interview conducted by my co-teacher. All the participants agreed to allow me to use their reflective journals as part of the study and all agreed to be interviewed. I do not feel as if pressure was applied since the assignments were required regardless of use in the study. I think the participants enjoyed being able to voice their opinion on the strategies.

\section{Responses Collected}

Responses in this study were collected over the course of the semester from participants in an open-ended method. The reflective journals were open-ended in that the participants simply reflected on the lesson of the day. The participants were asked to describe the experience by writing how they remembered and perceived the lesson and strategy used to present the lesson. They were asked to address both the process skill presented and the co-teaching that was modeled. There were no specific questions in the reflective journals and no set limit on how much they were to write.

Interviews were conducted at the end of the study, but not by me, the researcher. The reason for this is to alleviate any pressure the participants may feel to say what I want to hear. The interviews were conducted by a trained instructional assistant who has had experience with qualitative research. Interviews, according to Bogdan and Biklen (1998), are "used to gather descriptive data in the subjects' own words so that the researcher can develop insights on how subjects interpret some piece of the world" (p. 
94). The questions are semi-structured in that they are not pointed, but do tend to keep the focus on the topics of the study. The interviews were conducted with the co-teaching pairs instead of individually. This allowed for some dialogue between the pairs to reflect and share experiences together and with the interviewer. The interview questions were as follows (See Appendix D also):

- Describe how you came to understand the science process skills.

- What would I see if I walked into your classroom while you were teaching the science process skills?

- Describe how you came to understand co-teaching.

- How do you think you would use the strategy of co-teaching in an elementary science class?

- Would you agree that the university methods course has prepared you for teaching in an elementary science classroom? Why or why not?

At the end of the study, it was obvious that the interviews were not as descriptive as had hoped. One reason for this is that the interviewer may not have pursued the responses in depth or that the questions may have been too broad. The data used to answer the research questions does include interview responses, but not to a great extent.

Autobiographical journals were also used in this study by me, the researcher, and my co-teacher in the project. The co-teacher is also in higher education and is trained in science methods including the inquiry strategy. She and I wrote an autobiographical journal describing the experience from our perspective as co-teachers in this class. These journals gave another perspective on the concerns and anxieties we felt in presenting the 
lessons as co-teachers. Table $\mathrm{D}$ lists the format of the responses collected as well as which research question is addressed with each format (see page 48).

\section{Research Design}

This study was a naturalistic inquiry using hermeneutics as the theoretical orientation. Patton (2002) writes the foundational question of hermeneutics as, "What are the conditions under which a human act took place or a product was produced that make it possible to interpret its meaning?" (p. 113, 2002). This study explored the experiences and perceptions of pre-service teachers learning about process skills and co-teaching in the classroom to more effectively understand science instruction as a part of their professional training program.

Patton (2002) says that hermeneutics reminds us that the meaning of something will depend on the specific context in which it was seen or created. He says, "hermeneutic theory argues that one can only interpret the meaning of something from some perspective... whether one is reporting on one's own findings or reporting the perspectives of people being studied (and thus reporting their standpoint or perspective)" (p. 115, 2002).

In my study, the participants described their lived experience through reflective journal entries and interviews. The co-teacher and I also wrote memos on the daily happenings and commented on perceptions of lessons and interactions with the participants. With this data, a full and thick description of how the pre-service teachers developed an understanding of and perceived process skills and co-teaching is seen in vivid detail and in the context of which it evolved. 


\section{Table D}

How the research questions are answered with the responses collected

\begin{tabular}{|c|c|}
\hline Research Question & $\begin{array}{c}\text { Format of responses used to answer the } \\
\text { research question }\end{array}$ \\
\hline $\begin{array}{l}\text { How do pre-service teachers develop an } \\
\text { understanding of science process skills for } \\
\text { scientific inquiry? }\end{array}$ & $\begin{array}{l}\text { Reflective journals, interview question } \\
\text { number one, autobiographical journals }\end{array}$ \\
\hline $\begin{array}{l}\text { How do pre-service teachers perceive the } \\
\text { use of science process skills for scientific } \\
\text { inquiry in the classroom? }\end{array}$ & $\begin{array}{l}\text { Reflective journals, interview question } \\
\text { number two, autobiographical journals }\end{array}$ \\
\hline $\begin{array}{l}\text { How do pre-service teachers develop an } \\
\text { understanding of co-teaching strategies? }\end{array}$ & $\begin{array}{l}\text { Reflective journals, interview question } \\
\text { number three, autobiographical journals }\end{array}$ \\
\hline $\begin{array}{l}\text { How do pre-service teachers perceive co- } \\
\text { teaching in the classroom? }\end{array}$ & $\begin{array}{l}\text { Reflective journals, interview question } \\
\text { number four, autobiographical journals }\end{array}$ \\
\hline $\begin{array}{l}\text { How do science process skills instruction } \\
\text { and co-teaching strategies impact pre- } \\
\text { service teachers' attitude towards learning } \\
\text { and praxis? }\end{array}$ & $\begin{array}{l}\text { Reflective journals, interview question } \\
\text { number five, autobiographical journals }\end{array}$ \\
\hline
\end{tabular}

Analysis of the Responses

The data were analyzed using an analytic induction method. Bogdan and Biklen (1998) refer to analytic induction as a technique used to "develop a descriptive model that 
encompasses all cases of the phenomena" (p. 63). In this study, I collected data through the reflective journals, interviews, and autobiographical journals to understand how the participants developed an understanding of and perceived process skill instruction and co-teaching. I used coding and reflective memos to group the data into themes that describe the participants' lived experiences and perceptions.

Coding is a system to organize the data. Bogdan and Biklen describe coding from this perspective,

As you read through your data, certain words, phrases, patterns of behavior, subjects' ways of thinking, and events repeat and stand out...You search through your data for regularities and patterns as well as for topics your data cover, and then you write down words and phrases to represent these topics and patterns (p. 171).

The data were read many times and codes were assigned as they developed from the data. This was a multi-layered task; once a code was assigned, there was sometimes a more specific code applied to the data until the data were as organized as possible. The type of codes used was mainly the subjects' way of thinking about people and objects described by Bogdan and Biklen (1998). There were 31 codes used that described the process skill instruction and co-teaching, but also include emotions and anxieties as well.

Memos were also used to organize the data. Bogdan and Biklen (1998) suggest using memos to write to yourself as the researcher during the fieldwork to make sense of the data. The memos serve as a way of reflecting on the data by brainstorming ideas of what may be occurring and what is hoped to be gained. The memos also serve as a good way to remember specific instances in the data that may affect the analysis. Basically, 
these memos written throughout the fieldwork helped me as the researcher gather my thoughts and organize them to better conduct the entire study effectively and efficiently.

\section{Validity and Credibility}

Generalizability, applying findings to a larger population, is not the goal in qualitative research. Qualitative research produces rich descriptions about a smaller number of people or cases to increase the depth of understanding about those situations. Validity in qualitative research focuses on the researcher. Patton (2002) explains this:

"The credibility of qualitative methods, therefore, hinges to a great extent on the skill, competence, and rigor of the person doing the fieldwork" (p. 14). He goes on to say, No straightforward tests can be applied for reliability and validity. In short, no absolute rule exists except perhaps this: Do your very best with your full intellect to fairly represent the data and communicate what the data reveal given the purpose of the study (Patton, 2002, p. 433)

In this study, I used three methods to ensure the validity and credibility of the analysis of the responses. These methods were a) triangulation of the data, b) member checks of the interview transcripts, and c) removal of as much bias as possible as the researcher and co-instructor in this project. Methods triangulation was used specifically to examine the consistency of the responses. The reflective journals were done over the course of the semester, so therefore, the feelings and concerns of the participants were likely to change as the project progressed. The interviews conducted at the end of the semester have some of the same themes as the latest reflective journals. 
Member checks were employed for the transcripts of the interviews. The participants were interviewed in co-teaching pairs, and each pair was allowed to review the transcript of the interview to see if any discrepancies existed between what they said and what was transcribed. This was a good way for the participants to make sure what they wanted to discuss and reveal was interpreted by the transcriptionist correctly.

Observer effect was a concern in this study because I was also the instructor in the course. I take my view of this from Bodgan and Biklen (2002) when they explain that the researcher should "lighten up" when worrying about subjectivity (p. 34). Bogdan and Biklen stress that being open to the research experience and the direction the research takes your study is more important. It is imperative that the researcher be open and honest about having ideas about the direction of your study and not be defensive about eliminating bias. I discuss this issue more fully in a postscript at the end of the manuscript.

\section{Confidentiality and Ethical Considerations}

In order to maintain confidentiality of the participants, I did not use their names in any publication of the study including this paper. The participants agreed that their names will not be used. I could not keep the participants' names confidential from me, the researcher. As the co-instructor, I got to know all the participants as students in the class. I also knew what the participants discussed in their reflective journals and their interviews. In order to alleviate some stress in the interviews, I employed the services of an instructional assistant to conduct the interviews. He is trained in qualitative research 
and was able to probe the participants for their perceptions of inquiry-oriented instruction and co-teaching.

Merriam (1998) warns against invading the private space of the participants in interviews and other settings. This ethical handling of the participants is important in gaining their trust and respect. I was present in the university classroom, so the participants would feel comfortable with my presence, but I was not present in the interviews. Hopefully, this allowed for the most accurate data to be gathered. I did strive not to invade their personal space in the classroom or be judgmental when dialoguing with the participants in the classroom setting. I truly wanted the participants to feel comfortable in describing their understanding and perceptions of inquiry-oriented instruction and co-teaching in an elementary classroom. 


\section{CHAPTER FOUR}

\section{Analysis of the Responses}

The responses in this study were analyzed using hermeneutics. The responses collected were interpreted based on the context of the situation - in this case, an elementary science methods class where pre-service teachers were learning process skills and co-teaching. The journal entries, lesson plans, interviews and memos from the coteachers were examined for general themes and coded with major topics. The major codes then led to the creation of more specific codes in order to create an understanding of how pre-service teachers came to know and perceive co-teaching as a method to enhance their learning of science process skills in an inquiry classroom. The five research questions follow with the responses that emerged from the inductive analysis of the data.

Research Question One: How Do Pre-service Teachers Develop an Understanding of Science Process Skills for Scientific Inquiry?

The responses collected to answer this question show how the pre-service teachers demonstrated an understanding of the process skills in their own terms and by explaining how they performed the skill in the activity as it was presented in the coteaching method. The definition of the skill involves what the students thought of the actual skill and then how they recognized of the importance of possessing such a skill, especially an elementary student. Some participants, however, felt challenged when learning the skill and expressed their frustration, and sometimes enlightenment, by 
describing how they felt learning the skill. Lastly, a few participants noted a change over time in the development of their understanding of process skills by learning through performance of the skill. Over the course of the semester, the participants saw the skill modeled and performed the skill personally, therefore learning the skill through practice. Examples of all these findings follow.

\section{Defining the Process Skills}

Of the 24 participants, 21 gave rich details about how they understood the process skills in at least one science process skill in their reflective journals. Since the reflective journals were intended to be open-ended, the participants were not asked to define them; they defined them as their way of reflecting on the lesson and describing their experience with the lesson.

One of the participants who defined process skills as part of their reflective journal writes that communication is "expressing yourself clearly to the scientific community." Another participant wrote that observation "is using your sensory skills." A further example of defining observation written by a participant is that observation "teaches students to notice the little aspects of an object that they might overlook." Finally, a participant refers to inference in one of his reflective journals by saying, "when you are inferring some type of information you need to use many abilities in order to get a better answer. The most important way you can infer is to think." 
Process Skills as Useful Tools of Society

All but one participant mentioned in their reflective journal or interview that the science process skills are useful skills to possess in modern society. Twenty-three of 24 participants referred to the process skills as keys to functioning in today's world community either by being scientifically or technologically literate or by simply using the process skills in daily life. In a reflective journal entry written after the co-teaching of the particular skill in question, one participant describes observation, a process skill, in terms of its effect on science and technology, “(observation) is a very important skill for anyone to have. It is the epicenter of many discoveries and inventions that help form our diverse and innovative society". The participant goes on to say, "it allows a person to make judgments of their surroundings and important things that effect (sic) their environment." Another participant, in a reflective journal entry, says, "Observation is an important tool to have in any situation. A good observer is someone that is always noticing things that go on around them."

The next two examples are of participants describing two of the process skills as life skills. Again, these are from reflective journal entries written after the co-instructors have presented an inquiry lesson on these skills.

Measurement and observation are both skills that everyone needs to know as life skills. These are both skills that will not only be used often in science, but they will also be used in other subjects such as math and everyday activities. Measurement is also used in driving. 
Measurement is a life-long skill that the students will use for the rest of their lives.

For example they will use it to measure ingredients for recipes, experiments, or to build things.

The participants have taken these skills and related them to useful tools to have in not only school, but society as well.

\section{Learning as a Rewarding Challenge}

Of the 24 participants, 18 expressed frustration with trying to successfully complete the activity used to teach the process skills. The first activity presented by the co-instructors to the participants involved observation of drops of water. The participants had to name more than just a few characteristics. They were asked to name a minimum of ten just to prod their thinking skills. The lesson with rocks was basically the same: the participants were required to name characteristics of a common rock that they found near their home and brought to class. Also mentioned in this section is the lesson on measurement. This lesson called for the students to estimate the volume, mass, length and width of common objects and then to measure the objects with common equipment to see how close their estimations were.

A participant writes in her reflective journal:

When we were asked to list ten characteristics of water, I thought it would be impossible. However, when you are forced to look for things, you become creative and start looking for less obvious characteristics. You have to move beyond just visual characteristics and use all your senses...to explore and describe. Looking and seeing are just the beginning of observing; it involves hearing, touching, smelling, and tasting as well. 
Another participant who expressed frustration, but later enlightenment writes, "When you observe common things you could be very surprised to find out that they may not be as much alike than you thought. When you find something out like this through observing, it feels really good."

Overcoming the difficulty of the activity was the analogy for three participants. One of these writes in a reflective journal, "The outcome of the observation was not what I expected it to be... When we were told to list ten characteristics of water I thoughtNEVER! We will never find that many; water is clear and liquid!" She says later in the journal, "The observation became easier as time progressed." Another participant overcoming the challenge of the activity relates the activity to her awareness of herself. She writes favorably about the experience as it has affected her skills of observation. She writes,

I never realized how many ways that there are to describe items, especially everyday items. These activities made me think of (things) that I would normally not even have noticed. These activities also showed me that I sometimes miss the little things in my environment...things that you have to slow yourself down and look at. (One activity) was frustrating because of my lack of ability to notice detail right away. Although frustrating, (it) was an excellent example of observing and how people often look at the whole picture and miss the detail. At first, observing water and coming up with the...descriptive qualities was also frustrating. As I calmed down and began to think about the droplets, I began to benefit from working hard to find out about water. I used many more of my senses, I normally would have just used sight... 
Twelve participants mentioned their lack of the process skill inherently and were quite frustrated with that fact. One of these writes in a journal, "The lesson on measurement was difficult. I quickly discovered that I nor anyone else in my group was good at making estimations." Regarding measurement as a process skill, one participant cites measurement as a reason she was not successful in elementary science.

Measurement has never been one of my favorite activities. It is the main reason I dislike science labs so much. I have never felt very confident in my ability to measure or estimate measurements. I am not comfortable making guesses and then finding out exactly how far off I was from the correct answer. I really just don't like to estimate and measure.

A more assertive student is quite emphatic with her account of learning measurement and estimation, "I hate it; it's that simple." However, as another participant writes, the reason for the lack of this skill is clear, but there is more to it: "People don't like to be proved wrong, but estimation is an important part of life as well as science."

\section{Learning through Experience}

Participants indicated that they learned the skills over the course of the semester through the performance of the activities in the classroom and by co-teaching the skills through microlessons. In the interview conducted at the conclusion of the study, nine of the 12 co-teaching pairs referred to learning through performance of the skills. For example, in an interview with her co-teaching partner a participant comments,

We were introduced to them (the process skills) and we had to use them in some way-either by writing about it in our reflective journals or by teaching something 
about it. (These methods) encouraged us to critically think about the things we were going to talk about... (We learned) through the activities, the journals, through the co-teaching process. Through this, we gained a better understanding of the process skills.

Another participant writes in a reflective journal a comment referring to the observation inquiry lessons where the students examined drops of water and then, later, a common rock found near their home. She writes, "I have to admit that I never thought students could learn so much from just observing drops of water or manipulating a rock." This comment refers to an enlightenment of such for the student, "People do not realize they are learning through observation until they are given a lesson like the water and rock ones. There are many more things that you can find out about something by carefully observing." This category shows her awareness of her learning as a result of the experience.

Also in the interviews, 4 of the 12 co-teaching pairs expressed that it was the modeling of the inquiry strategy by the co-teachers that allowed them to come to learn the skills over the course of the semester. One participant says, "Through the microlessons that were taught they showed us what they (process skills) were and how you go about (learning) science...through seeing it done and observation, they gave us an understanding." Another participant comments in a separate interview that the way he learned the process skills was through "a lot of activities; a lot of hands-on stuff; like a lot of the activities we did in class were hands-on, and I think that's when you really learnwhen you actually get in there and do stuff." 
Eight participants commented that after they saw the inquiry strategy modeled, they had the freedom to explore ways to complete the activities - which is typical of inquiry style. One participant writes in a reflective journal, "The lesson we did in class on measurement was interesting because it allowed the students to find their own ways of measuring...I feel we learn more when we are encouraged to use our imaginations as well as have a hand in what is going on in the classroom." Another participant writes, In class we had different ways of learning skills with the various activities that we completed. Prediction - for example, we did a bridge and we had to predict how strong it would be and we had to communicate with one another to design a bridge that would be proper for holding 50 grams.

Five co-teaching pairs of participants even mentioned in the interviews that the modeling was not common in some methods classes. One participant says, "We learned process skills hands-on; she (myself, the co-instructor) let us actually do the activities instead of just handing us a sheet of paper and saying, 'This is what you can do with your students.' She actually let us do the activities for ourselves and experience them."

Research Question Two: How do Pre-Service Teachers Perceive the use of Science Process Skills to Implement Scientific Inquiry in the Classroom?

To answer this research question, the data is grouped into two main sections. The first section details the importance of learning the process skills by elementary students. In order to show this importance the participants generally wrote in a journal or reflected in an interview that students needed the skill or needed to be taught the skill. The second section shows how the pre-service teachers would use these process skills in their own 
classroom. The data from the use of this skill in a classroom was overwhelmingly positive. The participants mentioned using the skill in the future in most of their journal entries.

\section{Process Skills as a Necessity}

When reflecting on the process skills in their reflective journals, 20 of the 24 participants mentioned how the process skills they learned were necessary in teaching children how to deal with the world around them. A participant reflects on the way children discover the world around them. She writes, "Children can realize things on their own by using their senses to find out things they do not know." Another participant writes about the discovery as well, which is an important part of inquiry learning. She writes, "Observation is a key skill in elementary schools...These process skills are being used in teaching science. Children rely mainly on their sensory experiences for reflecting and acquiring knowledge. Their perceptions are based on first-hand experiences." The senses are defined by one participant who writes, "Children use their five sense organs (seeing, hearing, touching, smelling, and tasting) to explore and make observations."

\section{Process Skill Instruction as a Necessity}

Nine participants saw the instruction of process skills in an elementary classroom and the inquiry method of instruction of process skills as a necessity, thereby illustrating their perception of the use of the process skill. A participant writes in a reflective journal, "Teaching students the proper way of measuring is very important because it is a skill they will use the rest of their lives." Another participant goes further to describe how teaching the skills can be beneficial. 
As they (students) enter school it is a teacher's job to focus these skills so that they can be used to solve problems, formulate hypotheses, and understand relationships between related items. With the help of teachers, students will utilize their observation skills to perform well in and out of the classroom.

Illustrating the necessary inquiry method to teach process skills, a participant writes, "While children may forget a science lesson they've been taught, process skills are more likely to remain with them and be useful throughout their lives. Children learn science more effectively by DOING science." Thinking skills that are enforced with the inquiry method are mentioned by five participants. One of these writes, "The process skill of observation helps foster creative thinking; after developing this skill, students will become more critical of what they see and they will examine things more thoroughly."

\section{Process Skills in the Classroom}

All 24 of the participants indicated that they would use the process skills in the classroom. Not one participant wrote or said that he/she would not use process skills. The participants seemed to have agreed on the importance of the process skills. The participants revealed their intention to use the process skills in both general and specific ways. One participant writes, "I feel that observations like this one can be very effective on children in an elementary school science classroom. I will definitely use these when I become a teacher." Another general use of the skills is described by a participant where she says, "I think with every science lesson you need to have communication. I think that's a valuable force in science. I would do a lot of experiments where kids could work hands-on and actually see what they are doing and how things are classified." 
A specific example of how a participant would use the process skill observation is, "To teach this (observation) in a classroom, I would have a volunteer come and walk around the room and then go back into the hallway. After that person leaves, I would ask the students questions... what color was their shirt, were they smiling...this will enable the students to memorize things easier by using their observation skills to analyze information given to them." Another participant writes, "I think it would be fun to go outside and measure different objects."

Several participants not only revealed how they would use the process skills, but also spoke of their importance. One writes, "Incorporating observations into the classroom helps students think critically, use their prior schema, and use their imaginations." Another participant mentions critical thinking also by writing, "Observation causes students to think critically about things." Lastly, a participant writes, "I think basing science not on learning and memorizing facts, but on learning skills and how to do skills is more important."

\section{Research Question Three: How Do Pre-Service Teachers Develop an Understanding of}

\section{Co-Teaching Strategies?}

The responses given for the development of understanding co-teaching focuses on the roles that the participants gleaned from the modeling of co-teaching strategies. The responses in the interviews and reflective journals show that the participants defined their understanding of co-teaching by describing what they saw from the co-teachers and how they think that role would be beneficial in the classroom. The roles that seemed to emerge from the data are: 
- emotional supporter,

- classroom manager,

- materials manager,

- creative consultant, and

- instructor.

The participants also describe how they feel they learned more over the course of the semester as a student in the methods class by the co-teaching instruction.

\section{Co-teacher as Emotional Supporter}

Seven of the 24 participants described co-teachers as emotional supporters in the classroom based on what they saw and what they experienced during microteaching. One of the participant writes in a reflective journal, "I observed that the teachers seemed more relaxed and worked together as a team to convey the message of the lesson." Another participant refers to microteaching when she writes, "I realized it took much less effort on the teachers' part to teach a lesson."

Two of these participants refer to the future use of co-teaching. One participant illustrates the role of emotional supporter by writing, "I think that co-teaching would also have a more relaxed environment, because you would never have to worry about forgetting something, because the other teacher would be there to help you." Another writes, "I think co-teaching is a lot of fun because you're not doing all the work yourself and it takes a lot of stress off one person." 
Quite simply, the participants seemed to agree that it would be easier to teach a lesson if someone else was there to help pass out materials because it would speed the lesson along and save time in the classroom. Of the 24 participants, 19 referred to coteaching in the role of materials manager seeing more efficiency in the classroom. One participant illustrates the role by describing what she saw in the methods class, "I saw that two teachers made the lesson go more smoothly. Materials got to everyone quicker, and the students received individual attention." Another observed, "One teacher gave instruction for the lesson and told us what we needed while the other teacher prepared the needed materials and helped with the distribution of the materials."

Referring to the future use of co-teaching, one participant says, "Co-teaching allows for one teacher to explain the directions while another is passing out the materials." Another participant echoes this and says, "Co-teaching is helpful when one is teaching and the other passes out the papers or they both could pass out supplies...in order to get things finished quicker."

\section{Co-teacher as Classroom Manager}

Before the data from the participants is given, a note from one of the autobiographical journals must be presented. My co-teacher in the study wrote, "We almost ruined the lesson today because we left out a crucial step in the activity. Without that step, there would have been no way to successfully complete the activity. Thankfully, we realized it, corrected it and admitted our mistake to the class." Several reflections refer to this mistake so the autobiographical journal comment is important. 
The participants felt that the co-teacher was important in being a safety net-someone to fall back on when things go awry.

A couple of references were made to this mistake and mentioned in reflective journals as an illustration of how beneficial it is to have a co-teacher. One participant writes,

In an unanticipated situation, it is good to have two teachers, one who can supervise the students and another to fix the problem or deal with the situation. $\mathrm{He} / \mathrm{she}$ can leave the room if needed. In addition, the problem with the lesson may not have been identified until the end with only one teacher. This would have cost valuable time and the lesson may not have gone so well. However, since two teachers were present, the problem was identified early and the lesson was still a success.

Another participant writes, "In the co-teaching experience, we found it helpful to have another teacher assisting in the classroom... it is helpful to have a 'backup' or support if you were to lose your train of thought or leave out an important step of the activity."

In keeping with the classroom manager role, one participant touts the advantages of having a co-teacher by comparing the teachers to shepherds. He writes, "Teachers are like shepherds watching over their sheep. If one sheep leaves the flock the shepherd will leave the flock to find that one sheep. But, if a co-teacher is in the classroom, only one of the shepherds has to leave the flock attend to the stray." Attending to the students is not the only job of a classroom manager. One participant writes, "The co-teachers can also control how the students will react to the 'new stuff' on the desk. We all know that when there is something new on our desks we want to play with it one way or another. With 
two co-teachers in the room the students urge to play with the new item or items on the desk is curbed with two teachers watching."

Another job as classroom manager is being as efficient as possible with the discussions. A participant observed, "In our class it helped because the teacher asked a question and then wrote the answers on the chalkboard. There were so many answers called out, it helped to have two teachers to write them all down." In another sense, a participant writes, "Co-teaching is also good for students because if they have a question or can't remember what to do and the teacher happens to be working with someone else, they usually just sit there waiting and not doing work. Now, students have two people to ask questions and the work moves along a lot faster."

\section{Co-teacher as Creative Consultant}

Comments were made by six of the participants with regards to the increase in creativity with two teachers instead of just one. One of these participants writes in a reflective journal after observing co-teaching,

Co-teaching helped bring out more ideas for instruction. Two people were more creative with ideas; if only one teacher was present, some ideas or concepts may have never been emphasized. One teacher may not have even thought about some of the ideas that were introduced. The teachers worked with each other bouncing ideas off one another and collaborating to make the lesson more meaningful.

Another participant echoes this by saying in an interview, "Having two teachers means there is a wealth of knowledge about what is going on... Two teachers give better opportunity for discovery and learning than one because all students have a chance to 
learn." One participant reflects in her journal after performing a microlesson with her coteaching partner, "It is definitely true that two heads are better than one. I don't know how many times I have been in groups where we had to come up with an idea for a lesson or activity and every time I think I could never have come up with that idea on my own."

\section{Co-teacher as Instructor}

One of the jobs as a co-teacher, according to the responses is to give the students individual and group attention during a lesson to ensure each student's success. Eight comments were made regarding this particular job in the reflective journals. One participant writes, "The presence of two teachers allowed for more individual and group instruction. Each teacher had more time to give groups ideas or guidance. They were able to get to every group and lead them in the right direction." Another comment made that echoes this sentiment is, "The co-teachers walked around the room to help or answer students' questions. They never gave too much information when you asked a question. They wanted you to use critical thinking to come up with your own answer." Also written by a participant, "Co-teaching gave the students more perception on the lessons and without any dead time for the students to become distracted."

A specific example of how students received attentions is given by a participant in a reflective journal. She writes,

Groups and individual students received more attention than they would have with only one instructor. This was especially important with the measurement lesson...In my group, we specifically needed extra time with the instructor to learn how to use the balance... all groups received the attention they needed. 
Also, a participant writes how this is an important benefit for students. She writes, "The co-teaching process also made it easier for the students to ask for help without fear of ridicule."

Two participants commented on the methods of instruction used by the coteachers. One participant writes in a reflective journal, "The teachers seemed to take equal parts in the lesson. Both teachers alternately probed for further information and clarification of our findings. Another writes, "The instructor and the other teacher both gave us directions on how to do the observations that dealt with the water and the rocks. They fed off each other really easily. It seems they had put great preparation into the activity."

\section{Learning as a Result of Co-teaching}

The responses from the participants indicated that the participants learned over the course of the semester from the co-teaching instruction. Ten comments were made in the reflective journals and the interviews regarding the benefits of more effective learning through co-teaching. One participant describes the process while ending the comment with a statement on learning.

During the co-teaching lesson in our class, I saw both teachers sharing could answer all questions, pass out materials, and adequately explain the directions. With two teachers, we were able to have our questions answered quicker than usual because there was one on each side of the room most of the time. This allowed for understanding of the lesson because there was not much wait time for explanations. 
Another participant writes, "The use of co-teaching can distribute the responsibility of a lesson and/or class among two teachers by reducing the teachers' stress and effort while increasing the students' understanding of the subject."

The next two participants specify that the reason they felt they learned more from co-teaching instruction is because of the two points of view that can be seen with two different instructors. One participant reveals this development of understanding coteaching in an interview held at the end of the study.

The main concept I learned from co-teaching is teamwork. It seemed that instead of depending on one teacher to know everything about the lesson or subject, the responsibility was distributed to both teachers. It seemed mush easier to understand the idea being learned because I was able to hear it from two different points of view. I thought it was interesting that I was able to understand and interpret the meaning of the lesson from two teachers during the activity. Another participant also describes the development of understanding co-teaching in a separate interview.

I realized that two teachers instead of just one drastically changed how the lesson was taught and how I received it as a student. The two teachers were able to share both their points of view to better get across the subject of the lesson to each individual student. Hearing the two different points helped me as an individual to better understand the subject we were studying.

Finally, a participant sums her experience in understanding co-teaching, "I have realized co-teaching really is a great way for students to learn. I feel it helps students get things done faster with better understanding." 
Research Question Four: How Do Pre-Service Teachers Perceive Co-Teaching in the Classroom?

The participants describe their perceptions of co-teaching as observers of the method, and also describe their perceptions after co-teaching. The comments made regarding co-teaching in the beginning of this section show how the participants saw coteaching as a strategy while they were observing us, the co-teachers. The second section shows the perceptions of the participants after actually performing the strategy with their own co-teaching partner.

\section{Perceptions as Observers}

Eleven of the participants described learning co-teaching as a positive experience and even expressed a desire to use the strategy in the future. A participant reveals how she learned the co-teaching strategy in this statement made in an interview and reveals her perception of the strategy.

The only thing I really knew about co-teaching coming into this class was that two teachers teach at the same time; they work together with one another. But I learned you have to balance the weight between the two teachers and it's a really good experience and I would like to use it in my classroom.

Another participant writes in a reflective journal, "Every time we do a lesson with coteaching it is becoming more apparent how helpful it is for both students and teachers." More participants continue this theme of revealing how they learned the strategy over the course of the class and how they perceive its use in a classroom. Another participant writes, 
The more co-teaching is being shown to me with the different process skills the more I feel like I am actually getting to know it and understand its proper uses. It is becoming easier to comprehend and my first thought of me not using this in my classroom is disappearing.

The next comment echoes the sentiment expressed by the previous examples. He writes, When co-teaching was first introduced to me, I have to say that I was not totally in favor of it; mostly because I have control issues! Now I see the importance of implementing co-teaching in the classroom. I believe more can get accomplished by using co-teaching in an elementary classroom than by using the traditional teaching methods.

Four comments were made by participants who had serious doubts about whether or not co-teaching could be implemented effectively in an elementary classroom. Two of these even doubted the need to use co-teaching for the lessons that were taught. These perceptions are based on the observation of co-teaching in the methods class.

The first comment concerns the need for using co-teaching at all for the particular lesson. She writes, "I do not think this lesson needed to be co-taught. Maybe it would in lower grades but I really don't see that either. I feel that one teacher could have handled this on his or her own." Another participant refers to the appropriate use of the strategy by writing,

I think it would be hard to use it in your classroom, unless you have an aid or someone who's always there. But I guess you could work with a specialist, but it's hard to get with somebody to make time; it's a lot of work to coordinate a lesson with someone else when you could just do it yourself on your time. 
Yet another participant expresses her doubt about co-teaching in the future. She writes,

"I don't know if I would use co-teaching in my classroom." That doubt is further

illustrated in this comment,

One problem I have found with co-teaching is that there are two different styles of teaching. When there are two different styles this could confuse the students as they are trying to learn. Another problem with co-teaching is that the co-teachers may have conflicting ideas on how to teach the current lesson. I believe that coteaching is a good idea, but it does have its pros and cons.

When asked to comment on the co-teaching of the first lesson, one participant's comment in her reflective journal shows her skepticism about the presentation of the strategy.

As far as co-teaching is concerned, I think it looked easier to perform than it had to have been. It's difficult to make a lot of comments based on the fact that, as students, we did not get to see what is involved in planning a co-teaching lesson. We also were unable to see what was going on in the head of the presenters. People who appear cool and composed on the outside are not always feeling that way on the inside.

\section{Perceptions of Planning when Co-teaching}

In this section, the responses are enlightening because the participants are writing and talking about their perceptions after they have performed the co-teaching strategy with a co-teaching partner. These responses show the participants' concerns about planning when co-teaching. 
After they co-taught their microlessons in the methods class, 11 participants described a concern regarding the planning of lessons. The comments all have the same theme — not enough time and/or effort in planning — that affects their performance in coteaching the lesson. The first comment is from a reflective journal. The participant writes, "I feel that (name of co-teaching partner) and I did not spend as much time preparing as I would have liked." Another writes, "If (co-teaching partner) and I had a little more time planning, our flow could have improved." Yet another writes about communication, "We relied on the internet access and email, but that didn't work out best for us. I hope next time we will communicate better in person."

A participant reveals in the following comment that limited common planning time is a problem.

I think co-teaching is difficult. Maybe it is because we aren't officially teachers and have a million other things to worry about. Having to get together with someone else and trying to find times that are suitable for both are hard. I think this is why we struggle. We both go over the lessons individually at home and not together.

Another participant echoes this theme. She writes, "I really like that we were able to work with a co-teacher, but because of different schedules and such it was difficult to find time to get together and work." She goes on to comment on the work habits of her co-teaching partner, "Also it appears in my case one partner tends to do more work that the other. I don't like having to rely on other people, the phrase 'if you want something done right, do it yourself' is basically how I see things." This apparently was not the only participant who felt that way. Another writes, 
I don't mind doing the work, I even prefer to do things on my own because you don't have to depend on someone else. Plus you know that the work is going to get finished on time and it is going to be right. Don't get me wrong, I like my partner; it's just that she needs to accept some of the responsibility of the work. Perceptions of Presenting when Co-teaching

Fourteen pre-service teachers focused on some aspect of how they implemented their lesson. One participant writes in a reflective journal, "I believe co-teaching worked well in this lesson. We each talked about classification in different ways to help students understand the material better." Another comments, "I feel the lesson went smoothly and worked effectively. (Name of co-teaching partner) and I took turns teaching and both of us interacted with the students individually. I feel this microlesson was successful.” The next participant reveals that she is now more confident in teaching science. She writes, "I don't think I am very good at science and in teaching science I might be kind of nervous, but now I feel like I have the confidence to teach science.”

In keeping with the perceptions based on presenting the lessons, one participant says in an interview, "I like knowing I am not the only adult in the classroom. I hate to get up in front of a room and teach a lesson by myself, it scares me to death. But, having someone there with me is not bad. I like the comfort of having that person standing beside me." Yet another participant echoes this when she says, "It was reassuring to have another teacher buddy up in front of the class with me."

When considering the presentation of their lesson, nine participants reflected on the lesson with respect to speaking time. One of these participants writes, "I feel that (name of co-teaching partner) and I can improve this lesson by sharing the presentation 
portion of the lesson more equally." Another writes, "We did not know how to split the lesson up and what would be comfortable for us, and with this first co-teaching experience, it let us experiment with what we thought was to be done." Further reflection on this comes from another participant when she writes,

While planning was shared equally, the lesson itself did not end up being so. This is the difficult part of co-teaching: finding a balance. Most teachers are a dominant personality, and having two makes it difficult to find where one should stop and the other should pick up.

The next set of responses show that some did not speak enough during the presentation of the lesson, while some felt they spoke the whole time. A participant writes in a reflective journal, "During the first microlesson I did not speak as much as my counterpart, but the other co-teacher had the idea of doing the lesson so I let the coteacher go for it." Another participant admits she should have spoken more by writing, "If I had anything to do over again, I would have talked a little more."

The next examples show that these participants felt they did all the speaking in the presentation of the lesson. One participant writes in a reflective journal, "When teaching our microlessons on classification, we could share equal time talking and teaching the lesson. I am usually the 'take charge' type and I need to let the co-teacher have more input during the lesson." This sentiment is echoed by a participant in a reflective journal.

The next time we co-teach, we could make sure that each partner is able to say what they want to say during the lesson. I believe the last time I did a lot of talking and (name of co-teaching partner) really didn't get a chance to say much so I need to make sure I give her a chance to state her opinion. Next time, she 
will introduce the lesson which will give her a chance to talk more throughout the lesson.

Research Question Five: How do inquiry-oriented and co-teaching strategies impact students' attitudes towards learning and praxis?

For this research question, participants were interviewed at the end of the semester to see if they would reveal their thoughts on learning how to teach science and actually teaching science. The responses focus on what background the pre-service teachers had in science and elementary subject methods. The following five excerpts are from the interviews. The first example refers to the participant's background in learning science and how he wishes to incorporate methods learned in the class to use in the future:

My science in public school was_-get out your science book, read the chapter, do the questions at the end - this showed that science can be fun and that there are an unlimited amount of activities out there that can be used for science. I plan on doing a lot of experiments because kids love to do that, I like to do it. I don't like to sit and just listen to somebody talk out of a textbook.

This sentiment is echoed in the next excerpt that also mentions the participant's background in science:

This class has taught me a lot about how to go about teaching science. When I came in, I didn't have any idea how to use observation in science. It taught me activities to use to relate and open up to the students to get them more involved in 
learning about science. When I was in school, science and math were the worst classes for me and these activities are cool icebreakers you could use.

This particular participant indicates that the way science is taught in this class has affected her view of teaching science in a classroom. She says,

The activity was fun and simple, but we all got the point of the activity. Sometimes teachers make things so much harder than it needs to be, and no one even understands why they even did the experiment. I love the hands-on activities that we do in class, everyone gets involved and enjoys the assignments. I cannot wait to see what else you have planned.

The theme of the previous participant is mentioned by this participant in another interview. She says,

The activities are a lot more interesting than the ones I did in elementary. We always did questions out of a science book and you always dreaded it and the same way with math. What I like is, she would take activities from the graphics packet and she would show us how to do them so we would have them later on. The one from the microlesson, other people did as well, we saw really interesting ways to teach different concepts.

The next excerpt refers to co-teaching and how it has made her more confident in a classroom. She says, I think I am a lot more open to co-teaching; before, I wasn't really sure what it was all about. I feel comfortable with it now, where before, I don't think I'm very good at science and in teaching science I might be kind of nervous. But now, I feel like I have the confidence to teach it. 


\section{CHAPTER FIVE}

\section{Conclusions}

\section{Developing an Understanding of Process Skills}

To repeat the words of Huppert, Lomask, and Lazarowitz (2002), science process skills are a "major goal of science education, since those skills are not only needed by scientists, but by every citizen in order to become a scientifically literate person" (p. 807). In this section I will show that the pre-service teachers in the study communicated their understanding of the process skills by:

- relating how important these skills are to function in a science classroom and also society,

- $\quad$ seeing the process skills as a challenge to help show what the process skills are and why they are important for problem solving,

- admitting that actually performing the skill in the methods class led them to a greater understanding.

The pre-service teachers were able to describe the use of the process skills. As one participant says, "it (observation) allows a person to make judgments of their surroundings and important things.” Observation, like measurement, prediction, classification, inference, and communication are process skills. Being able to describe the importance of these skills shows an understanding of these process skills. Other participants mention that the process skills are useful in life with something as mundane as a recipe. It is obvious that the participants see that these skills transcend the classroom and would be crucial in teaching students to be problem solvers. 
A study by Harlen (1999) confirms that scientific literacy is increased when students learn process skills. The ability to use these skills allows students to translate their ideas into larger ideas to understand the world around them. The participants in this study also reveal that they learned from performing the process skills. This revelation goes with the countless number of studies that tout learning-by-doing. As Dewey announced to the Association for the Advancement of Science, students must be a part of the learning in order to gain the knowledge. Too often, Dewey says, science relies on the transmission of knowledge and not the process of science (Bybee, 2000). It is with this philosophy that inquiry gained its footing. It stands to reason, therefore, that the participants confirmed their acquisition of the knowledge of process skills by actually experiencing the skills in the classroom.

A large number of participants expressed frustration when participating in the activities. However, the reconcilement of the frustration led to greater understanding of the process skills by the participants. It is sometimes necessary to take students out of a comfort zone in order to show them new ideas. The participants noted that they were not sure of themselves when performing the activity, but then realized that they did indeed possessed the ability to perform the skills and learn them. One participant even notes she was "forced" to look at observation a different way, but when reached out of her comfort zone she saw observation in a different way. Another participant says that the task became easier as time progressed. Sometimes when something is difficult, frustration takes over and the students will give up on the task entirely. These pre-service teachers encountered difficulty, but did not give up on the task. In the end, the challenge led them to understand the process skills on a deeper level. 
A development in the understanding of process skills occurred as the study progressed. In the interviews, some of the pre-service teachers commented on how the modeling and performance of the process skills led to an understanding. They were able to look at the development of knowledge over the course of the semester and see that they were indeed learning the skills by engaging in the activities. The participants also contend that the modeling of the inquiry strategies led to the development of the knowledge of process skills. One student says, "Through seeing it done and observation, they (the co-teachers) gave us an understanding." Too often, pre-service teachers take science classes in order to fulfill a content requirement or pre-professional skills requirement, but are not exposed to the most current teaching method in these science classes. The Kelly (2000) study confirmed this thought with a study performed at Texas Christian University. The pre-service teachers in that study were taught science using the lecture mode. Given this, it is reasonable to say that the pre-service teachers would indeed learn more about inquiry and process skills if the strategies were modeled for them.

Perception of Process Skills

The responses given that illustrate the perception of the process skills by the preservice teachers are divided into two main sections. The pre-service teachers viewed the process skills by either describing how important it is for elementary students to learn them, or by detailing the ways that the skills could be implemented in an elementary science classroom. The pre-service teachers began with an explanation of how the 
process skills are a necessary part of science, and then described how process skill instruction is a necessary part of science instruction.

The pre-service teachers in this study relayed the message through reflections and interviews that process skills are of great importance to students. One participant wrote, "Children can realize things in their own by using their senses to find out things they do not know." This is the goal of inquiry teaching using process skills. Harlen (1999) says that process skills increase scientific literacy, and that students' knowledge of process skills increases their problem solving skills. The participants agree that students need to possess these process skills to discover their environment.

The pre-service teachers also agree that process skill instruction is crucial in an elementary science classroom. The responses reveal that the participants understand the importance of teaching the process skills using inquiry. There is an overwhelming agreement that students should be learning process skills in an elementary classroom so that they can, as one participant says, "examine things more thoroughly." They also mention that a product of process skill instruction may include better performance in the classroom. Arena (1996) writes that if students do not experience the joy of discovering that comes with inquiry, then they will be less likely to enter high school science classes later on and pursue a career in science. The repercussions of that are clear; there will be a lack of a scientifically-literate workforce.

The perceptions of the pre-service teachers regarding process skills reveal an agreement to use these skills in their future classroom. The pre-service teachers wrote in their reflective journals and discussed in interviews that they do indeed plan to use the process skills in their own classroom. Some discuss using the exact same lesson, and 
then others described how they would modify the activity. Regardless of how they implement the process skills, it is a positive finding that the students will take the process skill activities and use them at a later time. A common myth is that teachers do not use inquiry in the classroom. According to Barnett, et al. (2002), pre-service teachers need to see the inquiry performed by actual teachers to embrace the style of teaching. In his study, after watching actual teachers use inquiry instruction, 26 out of 28 pre-service teachers confirmed that they would use that method of instruction in their future classroom. Therefore, the findings of this study are congruent with other research done on pre-service teachers. As mentioned earlier, the pre-service teachers had to see inquiry done to decide whether they would use this method or not.

\section{Developing an Understanding of Co-teaching}

The data from the study to show how the pre-service teachers developed an understanding of co-teaching reflects the Heuristics for Productive Co-teaching as defined by the Roth and Tobin (2002) study. The roles that the pre-service described in their reflective journals echo the descriptors of co-teaching that filtered through a similar co-teaching study. It is interesting that while the pre-service teachers did not define these roles in sophisticated terms, they were able to find the essence of co-teaching by seeing the various roles a co-teacher encumbers. The roles that were identified through the preservice teachers' reflective journals and interviews match parts of the heuristics of the Roth and Tobin study (See page 29). Roth and Tobin (2002) defined these heuristics for their own studies, but I use it to see if the roles defined in my study are consistent with other research in co-teaching. It is reasonable to draw the conclusion that the roles that 
the pre-service teachers identify define what is common and acceptable in co-teaching, and therefore by defining these roles, the co-teachers have shown an understanding of coteaching.

The role of emotional supporter was identified by the pre-service teachers as one that defined a co-teacher. This role can relate to Roth and Tobin's heuristic Rapport. The participants in the study discuss how it is less stressful for the teachers because if one teacher is not performing well, the other teacher can step forward and maintain the instruction. One participant says, "You never have to worry about forgetting something, because the other teacher would be there to help you." The participants saw this as an emotional relief because they have not yet started teaching. However, even for experienced teachers, it is nice to know that in the classroom there is someone to step forward and keep the class flowing. It was interesting to see in my study that the preservice teachers are aware of how scary it can be in front of a group of students. I am satisfied that they see the other co-teacher as the safety net or backup if they need some help in their classroom.

Another role identified by the pre-service teachers in the study is materials manager. A participant observed, "I saw that two teachers made the lesson go more smoothly...materials got to everyone quicker..." This role is similar to Roth and Tobin's heuristic Variety of ways to participate. The co-teachers are able to see the need for getting materials to students as efficiently as possible and keep the students focused on the lesson instead of getting up and finding materials. The lessons not only are smoother, but also move quicker so that the students can start the lesson and have more time for discussion at the end. Materials are obviously important to the lesson, but should not 
take up large amounts of time. It was interesting that so many participants mentioned that benefit of co-teaching in their journals. Again, the pre-service teachers have recognized this aspect of classroom management. They have not been into the classroom much for their clinical experiences and yet they see that it is nice to have someone there to help manage the resources.

The role of classroom manager also emerged from the pre-service teachers' reflective journals and interviews. This role took on two forms-one of fixing mistakes and one of keeping on schedule. The first, fixing mistakes, was seen vividly from a lesson in which the co-teachers made a crucial mistake early in the lesson, but were able to recover to save the lesson. This role is reflected in the same heuristic as aboveVariety of ways to participate. However, specific attention is given to the steps taken to compensate for mistakes or missteps in the lesson. Because the co-teachers had a good rapport with each other, the mistake was quickly fixed and the lesson was successful. The participants noticed that this was an "unanticipated situation" as one wrote in which she also says, "It is good to have two teachers, one who can supervise the students and another to fix the problem."

The other part of the classroom manager role is keeping on schedule. The participants noticed that having a co-teacher meant that the lesson moved quicker and some tasks normally done with one teacher were able to be done more efficiently with two teachers. As one participant noticed, "in our class...the teacher asked a question and then (the co-teacher) wrote the answers on the chalkboard." One teacher would not have been able to take the time to write all the answers down and have time to discuss them at the end of the lesson. With a co-teacher when an open-ended question is asked where 
many different answers are anticipated, it is helpful to have two people write answers so that more time is spent in discussion of those responses. The Roth and Tobin heuristic that echoes this situation is Variety of opportunities. The co-teachers, without either of them seemingly in charge, took turns writing and discussing without any loss of instructional time. The co-teachers both wrote answers and took turns calling on students. In either case, it is evident that the co-teaching relies on coordination of efforts to make the lesson successful in the time allowed.

Creative consultant is another role that emerged from the data of the study. One pre-service teacher described the role as one that "helped bring out more ideas for instruction." Another participant says that there is a "wealth of knowledge" with two teachers in the classroom. This role defined by the participants relates to the Roth and Tobin heuristic Variety of discussion topics. Roth and Tobin (2002) identified the above heuristic as an observable phenomenon with co-teaching. When two teachers are in the room and there is Respect and Rapport (also heuristics), the creativity and discussion flows smoothly between the two. This particular phenomenon is noticed by the participants in this study. The co-teachers were able to share ideas and come up with ideas that the other co-teacher may not have thought about for the lesson. They also were able to see the benefit of doing so. Therefore, it is reasonable to conclude that the participants of this study have a good idea of how co-teachers can share ideas for the success of the students in the class. In their future classrooms, the pre-service teachers may not have access to a co-teacher, but at least in this study they have seen that another teacher can be a valuable instructional asset in meeting the needs of the students in their classrooms. 
The final role that surfaced from the responses is instructor. Given that the term instructor has many connotations, the reference with this role is one who assists the students in understanding the lesson. The participants of the study were impressed with the ease at which the lessons flowed because there were two instructors-people who could help the students with the content. As one participant noticed, "the presence of two teachers allowed for more individual and group instruction." In keeping with the Roth and Tobin (2002) heuristics, Inclusion of stakeholders fits this role. The co-teachers in this study went to each table on numerous occasions to make sure everyone knew how to proceed with the activity. As one participant observed, "they never gave too much information...they wanted you to use critical thinking." The pre-service teachers also noticed, in regard to the role of instructor, that we as co-teachers kept the class flowing smoothly by making sure we both took equal responsibility. A participant writes, "The teachers seemed to take equal parts in the lesson...both teachers alternatively probed for...clarification of our findings." Another writes, "They fed off each other easily...it seems they had put great preparation into the activity." With these excerpts from the reflective journals, the essence of being an instructor was seen by the participants. The participants gained a good understanding of being an instructor, but also a co-teacher. The participants in this study understand co-teaching and the roles of the co-teacher in conjunction with research.

\section{Learning with Co-teaching}

The responses from the reflective journals and interviews indicate that the preservice teachers felt they learned the process skills effectively with the co-teaching instruction. There was a development of understanding of co-teaching by the pre-service 
teachers. The pre-service teachers not only came to understand co-teaching, but also came to understand that they learned well with co-teaching. There were several participants who commented on this sentiment. One pre-service teacher writes, "I realized that two teachers...drastically change how the lesson was taught and how I received it as a student...hearing two different points of view helped me better understand the subject." Perhaps a reason for this is because the dynamics of the lessons are different with two teachers and the information is presented by two instructors. Even when two teachers teach the same content, there are going to be differences in the way it is presented - be it tone of voice, use of materials, or even emphasis on certain topics. Co-teaching can help students in any classroom learn more-in this case, a methods class, but any classroom is open for more learning. The fact that the pre-service teachers noticed that they learned better is of great importance to this study. Even further, the learning of process skills more effectively by pre-service teachers was a focus of this study. Seeing it happen is quite pleasing.

\section{Perceptions of Co-teaching}

The pre-service teachers in this study showed both positive and negative perceptions of co-teaching as a) observers of the co-teaching process, and b) as performers of the co-teaching strategy. It is interesting to see that the emotions and perceptions from the participants echo the sentiments of current classroom teachers who have co-taught in both inclusive and general education classes. According to the studies mentioned previously, these sentiments range from positive to negative as well. One issue to remember in this study is that these pre-service teachers have never co-taught in 
any other classroom and most have never been taught science process skills. Those confounding factors can cause anxiety in preparation and delivery of a lesson using coteaching.

\section{Observers}

As observers of co-teaching, the pre-service teachers were able to see that there could be benefits and did, indeed, identify those in the roles they saw emerge from the co-teaching. There were many comments, however, that reflected concerns with coteaching. One issue that arose was whether or not the lesson needed to be co-taught. I think the response to that would involve a question of whether or not the teacher wanted to co-teach the lesson for the sake of co-teaching or for the ease of having someone else assist in the classroom.

Once these questions are answered then the lesson can be co-taught successfully. It may not be necessary to co-teach a lesson, but some teachers may not have a choice in matter. Some administrations, according to a study done by Austin (2001), highly encourage co-teaching because of pressure from the community. Parents see that coteaching works in some classrooms, and they want to see it in every classroom. Some inclusive classes must have co-teaching with a special education teacher and a general education teacher. Therefore, the participant may feel that all lessons do not need to be co-taught, but if it is required, then there is no choice from the co-teachers. This point is certainly one I would open for future study.

Further sentiment expressed involved the practicality of co-teaching if you are not already assigned a co-teacher. This is certainly an issue with the limited funds of most schools. There are not generally two teachers assigned to each classroom to be co- 
teachers. Inclusive classes are different in that there is a special education teacher assigned to the classroom to co-teach with the general education teacher for the success of all students in that room - special education students or not. The problem with coteaching in this case is that one teacher may be more familiar with the content than the other as noted in the Weiss and Lloyd (2002) study where a special education does not feel comfortable at all with higher level mathematics. Therefore, the sentiment of the pre-service teachers who mention that co-teachers may not be available is true and would be a point for future study.

\section{Performers}

As performers of co-teaching, the participants noticed some areas of concern when co-teaching with a partner from the methods class. The first is planning. The coteachers are not negative with the concern, only expressing that they wished they had met more to plan the lessons together. They cite their work and class schedules as the cause, but agree that with more planning, the lesson could have been more successful. This is a concern with in-service teachers as well. Cook and Friend (1995) identify planning as one of the concerns expressed by co-teachers. Cook and Friend suggest a minimum of one half hour to plan the lesson, divide the tasks, and decide the basic format of the lesson. The participants did not state how much time they devoted to co-planning, but one participant admits, "we relied on internet access and email...I hope next time we can communicate in person."

The participants did see some positive benefits in presentation of the lessons. This is the second issue involved with performing the co-teaching lesson. The participants felt that they were not alone in the presentation and even say their confidence 
is improved in teaching science because they were able to do it with someone the first time. Like the participants of the Thomas and McRobbie (2002) and Roth and Tobin (2002) studies, the pre-service teachers felt that they understood how to teach science. The Thomas and McRobbie and Roth and Tobin participants felt that they were learners as well as the students in the classroom. In these studies, a pre-service teacher was paired with a university faculty to co-teach science. The pre-service teachers in those studies expressed an increase in their knowledge of instructional techniques. Regardless, the participants of previous studies and this study agree that co-teaching science together can be a good way to experiment with lessons and see what is successful and what is not.

With presentation, some participants of this study felt they were speaking the whole time or not enough. The participants were honest in their assessment of their cotaught lessons. This is an issue also defined by Cook and Friend (1995) and Vaughn, et al. (1997) who argue that co-teachers themselves should decide how much each will present and what the specific tasks are. Obviously, with disorganization of the tasks, there will be a disorganization of the lesson.

The reason for the concerns of the pre-service teachers is probably due to the fact that this was their first attempt at co-teaching. Gately and Gately (1997) identify three levels of co-teaching: beginning, compromising, and collaborative. These co-teachers are not only in the beginning stage of co-teaching, but they are in the beginning stage of teaching. The methods class is one of their first attempts at teaching. According to Gately and Gately, the beginning stage of co-teaching is when the participants ask superficial questions to establish boundaries. The pre-service teachers attempted to do 
this and teach a science lesson. Their attempt was admirable and they obviously learned a great deal from the experience.

\section{Gap between Theory and Praxis}

Responses that indicated an answer to this research question came from the interviews where the participants were able to synthesize what they had learned, match it with what they already have encountered, and reach a conclusion on praxis. The participants agreed that science was taught to them in lecture mode the majority of the time, but they have seen how science can be taught in a more constructivist and inquiryoriented method. The participants reveal that they saw the co-teachers present science the way that they, as teachers, would want to present it in the future. Some participants even mention a feeling of comfort with teaching science that they did not think they would ever have as an elementary teacher. The outcomes of this question are the same as the outcomes of a study done by Eick et al. (2003) where pre-service teachers discussed the use of inquiry strategies in the classroom. The outcomes of that study are:

- A feeling of comfort when learning to teach;

- The opportunity for critical reflection when modeling the teacher's lesson;

- A development of confidence in teaching and in managing student behavior; and

- The opportunity to see that inquiry can be done well in a classroom (Eick et al).

These match the outcomes of this study where pre-service teachers say they are more comfortable. A participant says, "I feel comfortable with (science teaching) now...I 
don't think I am good at science and in teaching science I might be kind of nervous. But now, I feel I have the confidence to teach it." This statement reflects the first and third outcome of the Eick, et al. study. Another participant says, "This class has taught me a lot about how to go about teaching science. When I came in, I didn't have any idea how to use observation in science. It taught me...to open up to the students and to get them more involved in teaching science." This sentiment is reflected in the third and fourth outcome of the above mentioned study. Overall, the pre-service teachers were able to see that science can be taught using inquiry and can be done well. They saw that they can do it as teachers because they have more confidence to do it in their own classrooms.

\section{Implications for Use in Science Education}

The findings of this study can be beneficial to science educators, classroom teachers, and pre-service teachers. Scientific literacy is of paramount importance, and that importance only increases as society and technology changes. Classroom teachers are called upon to teach students how to solve problems, not only in science, but other content areas as well. The basic process skills are integral to problem solving. When students can master the basic process skills, they are more equipped with the tools to function successfully in society. It is my hope that many more students will see that science is not an impossibly difficult subject, but merely a way of thinking and processing information. It is my hope as well that mastery of the basic process skills will open the minds of these students to enter science fields for their life's work.

Science educators at university and state levels can increase the emphasis on inquiry and process skills to pre-service teachers and classroom teachers. They can do 
this by actively seeking ways to integrate the process skills into classrooms. Materials, resources, and money can be allocated to finding ways to effectively teach scientific inquiry and the science process skills. Pre-service teachers will be exposed to inquiry, therefore, at the university level and carry that into their science classrooms as in-service teachers.

Co-teaching can assist in this goal of bringing more emphasis on inquiry to the classrooms. More often than not, classrooms are fully included-meaning special education students are learning right beside a regular education student. The special education teachers are called upon to be the co-teacher. More training of scientific inquiry would allow the special education teacher to take a more active role in coteaching in the classroom and not always rely on the classroom teacher. Universities can prepare special education pre-service teachers in inquiry learning and co-teaching if they are not already doing so. In-service teachers could be given opportunities to be trained in inquiry learning through their county or school board or even state department of education. The end result would be that the co-teachers would both be trained in inquiry learning and be able to comfortable bring that into the science classroom.

Regardless of whether the students in the room are special education or not, it should be the goal of every teacher to find the most appropriate strategy to teach his/her students. Inquiry learning and co-teaching can be two of those strategies attempted, but there are others supported by research. It is my hope that when a pre-service teacher is faced with an opportunity to use co-teaching, he/she will have a more positive outlook on this approach to classroom instruction. Pre-service teachers should evaluate the effectiveness of any teaching strategy. Nonetheless, the implications of this study show 
that these strategies of co-teaching and inquiry instruction, taken separately or individually, are an effective way to teach science in a classroom.

\section{Implications for Future Study}

In this study I was able to find out how the pre-service teachers were able to develop an understanding and perception of both process skills and co-teaching. In that development, there are some issues that arose that can be studied in the future. The use of process skills in an elementary classroom could be observed to see if in-service teachers are actually using these tools of inquiry. If they are not, perhaps a study could be done to find out what the reasons are. If they are, a study could be done to see what concerns the teachers have when using these process skills. With the emphasis on inquiry from the National Science Education Standards publications, teachers should evaluate if and how well these skills are being taught in the classroom.

The process skills themselves could be studied. Perhaps there are process skills that have emerged as a result of an increase in technology. A study could be done to see if students are lacking in a skill to effectively use that technology. There is a specific emphasis from the West Virginia Department of Education, for example, in the form of technology standards that are to be implemented in schools and accrediting institutions. The teaching of any additional skills to effectively use technology would be of great benefit to any classroom.

Studies in co-teaching could be done for a variety of reasons. Co-teaching could be studied more in depth at the school level and the university level. So often, techniques are used in schools, but not taught by universities to prepare the pre-service teachers. 
Studies could be done to identify where co-teaching is occurring and if it needs to become part of the university's curriculum. The dynamics of co-teaching could also be studied in greater depth. The conversations between the co-teachers before, during, and after the lessons could be recorded to see where the concerns are of all co-teachers involved. When concerns are identified, researchers could suggest ways to overcome these concerns. Co-teaching could be studied in different content areas to see if one area benefits more than the other. Generally, any future research on co-teaching would benefit those who are required to co-teach in their classroom.

Science education and co-teaching are going to continue to evolve as information is gained and society changes as a response to the new information. Society will respond to new issues and trends in educational research as it has for a long time. We never know where these trends will take us in our pursuit of the best education for our children. We do know that sometimes research tends to cycle, but my hope is that it spirals. With each new find in research, it would be of benefit to see how that find is grounded in previous literature, but also makes it way into future literature. 


\section{Personal Postscript}

I hear a knock at my office door in the late afternoon one day. "Miss Carter?" the voice says.

"Yes," I respond as I turn and see one of the student teachers I am supervising this semester.

"I have a question...," she trails off the end of the statement in a meek voice. "I don't know what to do for my third period class. I need help."

It is always those three words that perk me up and make me feel that I may be able to help a future teacher as he/she encounters the world of teaching. This day was a little different. She explained that her problem was that there were four adults in the third period class and no one knew what each was supposed to do with the students. The class was a general science class in a middle school. There was a classroom teacher assigned to teach the science, a student teacher for that classroom teacher (the student asking for help), a special education co-teacher, and a special education student teacher. The student described a classroom full of adults and students, but she did not see how all of them worked together. The classroom teacher was frustrated because she was doing all the instruction; the special education teacher was frustrated because she did not know the science that well; and both student teachers were frustrated because they were not sure what they were supposed to be doing for either teacher. I listened to her description realizing that I had no idea either. I had never had any training in co-teaching and would have no idea specifically what it looks like. This conversation is why I decided to do this study. As a science educator I wanted to see if process skill instruction could be 
enhanced with co-teaching, and also if pre-service teachers could benefit from seeing coteaching before they encountered it in the public schools.

I had two main concerns with this study. The first was my role. My role in this study was complicated. I had to be the researcher obviously, but I also had to be one of the instructors because I was given access to a class of pre-service teachers. I realized that I would be giving these pre-service teachers a grade at the end of the semester, and I also realized that the pre-service teachers knew this too. In order to ease the tension of being solely responsible for grading, I asked the co-teacher, a colleague who has also become a friend over the last few years of my doctoral work, to assist with the grading. She was also aware that the participants may not have been as honest and open even to her because of our positions as instructors.

Bogdan and Biklen (2002) address this issue in a section of their textbook, Qualitative Research in Education: An Introduction to Theory and Methods ( $3^{\text {rd }}$ edition). The question they pose and then answer is, "Doesn't the presence of the researcher change the behavior of the people he or she is trying to study?" (p. 35). They answer the question by saying yes, the researcher's presence is an influence on the data and is called observer effect. It is much like the scientific Heisenberg's uncertainty principle. This principle states that the electron microscope used to measure the position of the electron actually alters the velocity of the electron due to the heat it emits. Patton (2002) summarizes this by saying, "The physical world can be altered by the intrusion of the observer" (p. 326). The question then becomes: how much is the world changed? Patton suggests monitoring the effects and taking them into account when the data is analyzed. 
For my study, I adhered to the advice of Bogdan and Biklen (2002) by keeping the setting as natural as possible. My co-teacher and I did not treat the participants as subjects, but as students in our class. It was a familiar experience because we have both been teachers for a number of years. The students, of course, were aware of their roles in the study, but showed no outward signs of being research subjects. They never asked about the study or showed any interest in knowing how it was progressing. Their questions were only related to the work assigned and assistance needed for the lessons they were presenting. They almost seemed to forget they were research subjects until the interview process. This may have had some impact on the lack of depth in their interview responses. The participants were not accustomed to being interviewed. Their other classes do not require interviews, and it was probably their first time in that setting. The data that were much more helpful were the reflective journals. The participants are used to reflective journals as part of the assignment in their pre-service classes. The framework for the undergraduate program in education at this college is critical thinking so the pre-service teachers have been asked to do reflective journals in every class they have taken. This familiarity and practice in writing reflective journals would indeed allow them to open up more and be honest in those journals about their perceptions and lived experiences.

The other main concern was that of neutrality. From the conversation recounted at the beginning of the postscript, it is easy to see that I had a reason for wanting to study co-teaching. Bogdan and Biklen (2002) do address this concern, and their advice is for the researcher to "lighten up" (p. 34). I did not take this issue lightly at all, but I did relax knowing that this was going to be present no matter what I did or said. It is impossible 
for someone to separate past experiences and feelings and not allow those feelings to influence the lived experiences. Bogdan and Biklen (2002) suggest that researchers use the opportunity to become more reflective about who they are and how that may affect what they are doing rather than being defensive and insisting that they are neutral. Bogdan and Biklen recommend that the researchers be open to the fact that what they have experienced in the past will shape what they think about the study. I followed this suggestion and allowed my thinking to be shaped by the data that I was observing.

I began the study expecting the participants to gain knowledge of the process skills as well as co-teaching. I also expected them to be able to perform the lessons and co-teaching with little to no trouble. What I found was not exactly what I expected, but I was pleased with the results. I felt as if I held the process skill instruction to a standard and examined how they reached that standard. I would not do that in the future. The process skill instruction was prescribed and the data show that the participants can learn the process skills. Since I knew the process skills already, I did hold the students to my definition.

The co-teaching aspect of the study was much more enlightening. I did not have a clear definition of co-teaching. I had no expectation of how they would understand or respond to the co-teaching. There is no prescribed format of co-teaching in the literature, only suggestions and guidelines for what could be considered co-teaching. I had no prior experience with co-teaching. I met with my co-teacher to co-plan and have a tentative schedule of how the lesson would flow. Once we began to co-teach, we went through the lessons with ease, not always relying on the schedule, but taking it naturally to do what was necessary to keep the lesson going smoothly. I found that the data was much more 
rich and informative than the data for the process skills because of this flexible, inquiring disposition. I was impressed and proud of the data showing how the participants saw coteaching. As a researcher, I learned more from the data about co-teaching than I did about process skills.

My co-teacher also saw the reactions to co-teaching as much more enlightening than the process skill data. We de-briefed each lesson and expressed joy in seeing the pre-service teachers use co-teaching in different ways. Each co-teaching pair was a different mix of personalities and showed a different style. This was nice to see as a researcher, but could be a problem if co-teaching were to be implemented on a large scale in schools. I could see that not all co-teachers were able to present as successfully as others. The personalities and styles of each pair did not always match, but the coteachers did make a good effort to work together and present a good lesson to the class.

Overall, the study was successful in seeing how pre-service teachers perceive the topics, but especially co-teaching. I learned about my place in research as well as the place of the participants. I learned about my biases and preconceived notions, but I also learned to see the perceptions of the pre-service in the context in which they were being experienced. I learned to keep the research setting as natural as possible and expect anything from a study. Most importantly, I learned about pre-service teachers and the problems they encounter that will help me when I find the next student teacher knocking on my door for help. 


\section{References}

Abel, C.F. (2003, Fall). Heuristics and problem solving. New Directions for Teaching and Learning, 95, 53-58.

Akkus, H., Kadayifci, H., Atasoy, B., \& Geban, O. (2003, November). Effectiveness of instruction based on the constructivist approach on understanding chemical equilibrium concepts. Research in Science \& Technological Education, 21(2), 209-225.

Alparslan, C., Tekkaya, C., \& Geban, O. (2003, Summer). Using the conceptual change instruction to improve learning. Journal of Biological Education, 37(3), 133-138.

American Association for the Advancement of Science. (2001). Atlas of Science Literacy. Washington, D.C.: American Association for the Advancement of Science; National Science Teachers Association.

Arena, P. (1996, December). The role and relevance in the acquisition of science process skills. Australian Science Teachers Journal, 42(4), 34-39.

Austin, V. L. (2001, July/August). Teachers' beliefs about co-teaching. Remedial and Special Education, 22(4), 245-256.

Barnett, M., Keating, T., Harwood, W., \& Saam, J. (2002, October). Using emerging technologies to help bridge the gap between university theory and classroom practice: challenges and successes. School Science and Mathematics, 102(6), 299314.

Bogdan, R. C. \& Biklen, S. K. (1998). Qualitative Research in Education: An Introduction to Theory and Practice ( $3^{\text {rd }}$ ed.) Boston: Allyn and Bacon. 
Bybee, R. W. (2000). Teaching science as inquiry. In J. Minstrell \& E. H. van Zee (Eds.), Inquiring into Inquiry Learning and Teaching in Science (pp. 20-46).

Washington, D.C.: American Association for the Advancement of Science.

Chang, C., \& Weng, Y. (2002). An exploratory study on students' problem-solving ability in earth science. International Journal of Science Education, 24(5), 441-451.

College Pathways to the Science Education Standards. (2001) (E. Siebert, D. \& W. J. McIntosh, Eds.). Arlington, VA: National Science Teachers Association.

Cook, L., \& Friend, M. (1995, November). Co-teaching: guidelines for creating effective practice. Focus on Exceptional Children, 28(3), 1-16.

Cothron, J. H., Giese, R. N., \& Rezba, R., J. (1993/1989). Students and Research (Second). Dubuque, IA: Kendall/Hunt.

Craven III, J. A. (2002). Assessing explicit and tacit conceptions of the nature of science among preservice elementary teachers. International Journal of Science Education, 24(8), 785-802.

Eick, C. J., Ware, F. N., \& Williams, P. G. (2003, January/February). Coteaching in a science methods course. Journal of Teacher Education, 54(1), 74-85.

Freire, P. (2001). Pedagogy of the Oppressed (Myra Bergman Ramos, Trans.) (30th Anniversary Edition). New York: Continuum (Original work published 1970).

Gabel, D. (1984). Introductory Science Skills. Prospect Heights, Ill: Waveland Press.

Gately, S. E., \& Gately, J., Frank J. (2001, March/April). Understanding coteaching components. Teaching Exceptional Children, 33(4), 40-47.

Harlen, W. (1999, March). Purposes and procedures for assessing science process skills. Assessment in Education, 6(1), 129-145. 
Harris, C., \& Harvey, A. N. C. (2000, fall). Team teaching in adult higher education classrooms: toward collaborative knowledge construction. New Directions for Adult and Continuing Education, 87, 25-32.

Huppert, J., Lomask, M., \& Lazarowitz, R. (2002). Computer simulations in the high school: Students' cognitive stages, science process skills and academic achievement in microbiology. International Journal of Science Education, 24(8), $803-821$.

Inquiry Starters. Retrieved May 12, 2004, from http://www.asp.ucar.edu/ morrill/EDUC5385/inquiry_starters.html.

James Madison University College of Education. Co-teaching (College of Education). Retrieved May 12, 2004, from James Madison University: http://coe.jmu.edu/esc/Consortium_Co-Teaching.shtml.

Johnson, B. \& Christensen, L. (2004). Educational Research: Quantitative, Qualitative, and Mixed Approaches ( $2^{\text {nd }}$ ed.). Boston: Pearson.

Kagan, D. (1993, March). Snapshots from high school: Teachers' vs. professors' views. Educational Leadership, 50(6), 28-31.

Kelly, J. (2000). Rethinking the elementary science methods course: A case for content, pedagogy, and informal science education. International Journal of Science Education, 22(7), 755-777.

Kirkwood-Tucker, T. F., \& Bleicher, R. (2003). A self-study of two professors team teaching a unifying global issues theme unit as a part of their separate elementary social studies and science preservice methods class. The International Social Studies Forum, 3(1), 203-217. 
Krajcik, J., Blumenfeld, P., Marx, R., \& Soloway, E. (2000). Instructional, curricular, and technological supports for inquiry in science classrooms. In J. Minstrell \& E. H. van Zee (Eds.), Inquiring into inquiry learning and teaching in science (pp. 283315). Washington, D.C.: American Association for the Advancement of Science.

Lonning, R. A., \& DeFranco, T. C. (1994, January). Development and implementation of an integrated mathematics/science preservice elementary methods course. School Science and Mathematics, 94(1), 18-26.

Lunsford, S. (2002, February). In-Service Inquiry. Science Teacher, 69(2), 54-56.

Martin-Hansen, L. (2002, February). Defining Inquiry. Science Teacher, 69(2), 34-37.

Maxwell, J. A. (1996). Qualitative Research Design. Thousand Oaks, CA: Sage Publications.

McIntosh, W. J. (2001). Teaching Standards. In E. Siebert, D. \& W. J. McIntosh (Eds.), College Pathways to the Science Education Standards (pp. 1-24). Arlington, VA: NSTA Press.

Merriam, S. B. (1998). Qualitative Research and Case Studies in Applications in Education. San Francisco: Jossey-Bass.

Morrison, K. L., \& Marshall, C. S. (2003, December). Universities and Public schools: Are we disconnected? Phi Delta Kappan, 85(4), 292-297.

National Research Council. (1996). National Science Education Standards. Washington, D.C.: National Academy Press.

National Research Council. (2000). Inquiry and the National Science Education Standards. Washington, D.C.: National Academy Press. 
Padilla, M. J. (1990, March, 1). The Science Process Skills. Research Matters-to the Science Teacher(No. 9004). Retrieved October 2, 2004, from http://www.educ.sfu.ca/narstsite/publications/research/skill.htm.

Patton, M. Q. (2002). Qualitative Research and Evaluation Methods (3 ${ }^{\text {rd }}$ ed.) Thousand Oaks: Sage Publications.

Pizzini, E. L., Shepardson, D. P., \& Abell, S. K. (1991). The inquiry level of junior high activities: Implications to science teaching. Journal of Research in Science Teaching, 28(2), 111-121.

Plourde, L. A., \& Alawiye, O. (2003, September). Constructivism and elementary preservice science teacher preparation: Knowledge to application. College Student Journal, 37(3), 334-342.

Reiff, R., Harwood, W. S., \& Phillipson, T. (2002, January 10-13). A scientific method based upon research scientists' conceptions of scientific inquiry. Presented at the Annual International Conference of the Association for the Education of Teachers in Science, Charlotte, NC.

Roth, W.-M. (1998, June). Science teaching as knowlegdability: A case study of knowing and learning during coteaching. Science Education, 82(3), 357-377.

Roth, W.-M., \& Tobin, K. (2001). The implications of coteaching/cogenertaive dialogue for teacher evaluation: Learning from multiple perspectives of everyday practice. Journal of Personnel Evaluation, 15(1), 7-29.

Roth, W.-M., \& Tobin, K. (2002). At the elbow of another. New York: Peter Lang. 
Roth, W.-M., Tobin, K., Zimmerman, A., Bryant, N., \& Davis, C. (2002). Lessons on and from the dihybrid cross: An activity-theoretical study of learning in coteaching. Journal of Research in Science Teaching, 39(3), 253-282.

Rudestam, K. E., \& Newton, R. R. (2001). Surviving Your Dissertation (Second). Thousand Oaks, CA: Sage Publications.

Science Content Standards and Objectives for West Virginia Schools. Available from http://wvde.state.wv.us.

Simpson, D. (2000). Collaborative conversations: Strategies for engaging students in productive dialogue. In J. Minstrell \& E. H. van Zee (Eds.), Inquiring into inquiry learning and teaching in science (pp. 176-183). Washington, D.C.: American Association for the Advancement of Science.

Sterling, D. R., \& Goor, M. (1998, November). Science for your students? Intervention in School and Clinic, 34(2), 123-126.

Thomas, G., P., \& McRobbie, C. J. (2002). Collaborating to enhance student reasoning: Frances' account of her reflections while teaching chemical equilibrium. International Journal of Science Education, 24(4), 405-423.

Tolman, M. N., \& Hardy, G. R. (1999/1995). Discovering Elementary Science (Second). Boston: Allyn and Bacon.

Vaughn, S., Schumm, J. S., \& Arguelles, M. E. (1997, Nove/Dec). The ABCDEs of CoTeaching. Teaching Exceptional Children, 30(2), Teaching Techniques. Retrieved May 12, 2004, from Learning Disabilities Online: www.ldonline.org/ld_indepth/teaching_techniques/tec_coteaching.html. 
Weiss, M. P., \& Lloyd, J. W. (2002, Summer). Congruence between roles and actions of secondary special educators in co-taught and special education settings. Journal of Special Education, 36(2), 58-69.

Wunder, M., \& Lindsey, C. (1987, January). The ins, outs of co-teaching. Missouri Innovations in Education. Retrieved May 12, 2004, from Center for Innovations in Education: http://www.cise.missouri.edu/includes/toolbox/print-friendly.php. 


\section{Appendix A}

\section{National Science Education Standards}

\section{Science Teaching Standards}

TEACHING STANDARD A:

Teachers of science plan an inquiry-based science program for their students. In doing this, teachers

- Develop a framework of yearlong and short-term goals for students.

- Select science content and adapt and design curricula to meet the interests, knowledge, understanding, abilities, and experiences of students.

- Select teaching and assessment strategies that support the development of student understanding and nurture a community of science learners.

- Work together as colleagues within and across disciplines and grade levels.

\section{TEACHING STANDARD B:}

\section{Teachers of science guide and facilitate learning. In doing this, teachers}

- Focus and support inquiries while interacting with students.

- Orchestrate discourse among students about scientific ideas.

- Challenge students to accept and share responsibility for their own learning.

- Recognize and respond to student diversity and encourage all students to participate fully in science learning.

- Encourage and model the skills of scientific inquiry, as well as the curiosity, openness to new ideas and data, and skepticism that characterize science.

\section{TEACHING STANDARD C:}

Teachers of science engage in ongoing assessment of their teaching and of student learning. In doing this, teachers

- Use multiple methods and systematically gather data about student understanding and ability.

- Analyze assessment data to guide teaching.

- Guide students in self-assessment.

- Use student data, observations of teaching, and interactions with colleagues to reflect on and improve teaching practice.

- Use student data, observations of teaching, and interactions with colleagues to report student achievement and opportunities to learn to students, teachers, parents, policy makers, and the general public.

\section{TEACHING STANDARD D:}

Teachers of science design and manage learning environments that provide students with the time, space, and resources needed for learning science. In doing this, teachers 
- Structure the time available so that students are able to engage in extended investigations.

- Create a setting for student work that is flexible and supportive of science inquiry.

- Ensure a safe working environment.

- Make the available science tools, materials, media, and technological resources accessible to students.

- Identify and use resources outside the school.

- Engage students in designing the learning environment.

TEACHING STANDARD E:

Teachers of science develop communities of science learners that reflect the intellectual rigor of scientific inquiry and the attitudes and social values conducive to science learning. In doing this, teachers

- Display and demand respect for the diverse ideas, skills, and experiences of all students.

- Enable students to have a significant voice in decisions about the content and context of their work and require students to take responsibility for the learning of all members of the community.

- Nurture collaboration among students.

- Structure and facilitate ongoing formal and informal discussion based on a shared understanding of rules of scientific discourse.

- Model and emphasize the skills, attitudes, and values of scientific inquiry.

\section{TEACHING STANDARD F:}

Teachers of science actively participate in the ongoing planning and development of the school science program. In doing this, teachers

- Plan and develop the school science program.

- Participate in decisions concerning the allocation of time and other resources to the science program.

- Participate fully in planning and implementing professional growth and development strategies for themselves and their colleagues.

Source:

National Research Council. (1996). National Science Education Standards. Washington, D.C.: National Academy Press. 


\title{
Appendix B
}

\author{
National Science Education Standards \\ Science Education Program Standards
}

PROGRAM STANDARD A:

All elements of the K-12 science program must be consistent with the other National Science Education Standards and with one another and developed within and across grade levels to meet a clearly stated set of goals.

- In an effective science program, a set of clear goals and expectations for students must be used to guide the design, implementation, and assessment of all elements of the science program.

- Curriculum frameworks should be used to guide the selection and development of units and courses of study.

- Teaching practices need to be consistent with the goals and curriculum frameworks.

- Assessment policies and practices should be aligned with the goals, student expectations, and curriculum frameworks.

- Support systems and formal and informal expectations of teachers must be aligned with the goals, student expectations and curriculum frameworks.

- Responsibility needs to be clearly defined for determining, supporting, maintaining, and upgrading all elements of the science program.

\section{PROGRAM STANDARD B:}

The program of study in science for all students should be developmentally appropriate, interesting, and relevant to students' lives; emphasize student understanding through inquiry; and be connected with other school subjects.

- The program of study should include all of the content standards.

- Science content must be embedded in a variety of curriculum patterns that are developmentally appropriate, interesting, and relevant to students' lives.

- The program of study must emphasize student understanding through inquiry.

- The program of study in science should connect to other school subjects.

\section{PROGRAM STANDARD C:}

The science program should be coordinated with the mathematics program to enhance student use and understanding of mathematics in the study of science and to improve student understanding of mathematics.

Science requires the use of mathematics in the collection and treatment of data and in the reasoning used to develop concepts, laws, and theories. School science and mathematics 
programs should be coordinated so that students learn the necessary mathematical skills and concepts before and during their use in the science program.

\section{PROGRAM STANDARD D:}

The K-12 science program must give students access to appropriate and sufficient resources, including quality teachers, time, materials and equipment, adequate and safe space, and the community.

- The most important resource is professional teachers.

- Time is a major resource in a science program.

- Conducting scientific inquiry requires that students have easy, equitable, and frequent opportunities to use a wide range of equipment, materials, supplies, and other resources for experimentation and direct investigation of phenomena.

- Collaborative inquiry requires adequate and safe space.

- Good science programs require access to the world beyond the classroom.

\section{PROGRAM STANDARD E:}

All students in the K-12 science program must have equitable access to opportunities to achieve the National Science Education Standards.

\section{PROGRAM STANDARD F:}

Schools must work as communities that encourage, support, and sustain teachers as they implement an effective science program.

- Schools must explicitly support reform efforts in an atmosphere of openness and trust that encourages collegiality.

- Regular time needs to be provided and teachers encouraged to discuss, reflect, and conduct research around science education reform.

- Teachers must be supported in creating and being members of networks of reform.

- An effective leadership structure that includes teachers must be in place.

Source:

National Research Council. (1996). National Science Education Standards. Washington, D.C.: National Academy Press. 


\section{Appendix C}

\section{SCIENCE CONTENT STANDARDS AND OBJECTIVES FOR WEST VIRGINIA SCHOOLS}

\section{SCIENCE - POLICY 2520.3}

The science content standards identify what students should know, understand and be able to do in the natural sciences throughout their K-12 education. Because each content standard utilizes the knowledge and skills of other standards, they are designed to be used as an integrated whole. Although material can be added to the content standards, using only a subset of the standards will leave gaps in the students' scientific literacy.

\section{Doing Science:}

- Standard 1 - History and Nature of Science

- Standard 2 - Science as Inquiry

Knowing Science:

- Standard 3 - Unifying Themes

- Standard 4 - Science Subject Matter/Concepts

Context of Science:

- Standard 5 - Scientific Design and Application

- Standard 6 - Science in Personal and Social Perspectives

A three-dimensional instructional strategy model must be utilized to address the science curriculum and assure students' depth of understanding and breadth of knowledge.

\section{Standard 1: History and the Nature of Science}

The study of science as a human endeavor provides for the acquisition of ideas leading toward the current knowledge base that represents science content. The nature of science encompasses the basic values and beliefs that make up the scientific world view, how scientists go about their work and the general culture of scientific enterprise. Studying historical and current discoveries of scientists and scientific milestones provides students with information about how discoveries have influenced current scientific thought and advancements. Students should understand that the continuous development of scientific knowledge shapes history. The study of the history and nature of science clarifies scientific inquiry and the role of science in the development of world cultures.

\section{Standard 2: Science as Inquiry}

Science is a process of discovery. Students will engage in active inquiry through investigations and hands-on activities a minimum of $50 \%$ of the instructional time. Developing scientific literacy requires a learning environment in which students actively participate in meaningful hands-on activities. These investigations explore the natural 
world, require critical thinking and develop process skills. Learning activities are sequenced to shape, modify and develop students' knowledge in order for them to become independent inquirers.

\section{Standard 3: Unifying Themes}

Broad unifying themes complement the perspectives presented in the other content standards. These themes are fundamental to understanding and unifying the various science disciplines. Major unifying themes are systems, models and changes.

\section{Standard 4: Science Subject Matter/Concepts}

Science subject matter focuses on the scientific facts, concepts, principles, theories and models that are important for all students to know, understand and apply. Through the integration of the fields of science and the development of unifying themes, students will understand the interrelationships among biology, chemistry, physics and the earth sciences. Scientifically literate students will make connections in the formal education setting and will apply their knowledge and skills to daily life experiences. The objectives describe the specific subject matter/concepts that students are to master at each grade level.

\section{Standard 5: Scientific Design and Application}

Scientific design and application permits the extension of senses, the enhancement of the knowledge base, transportation of materials and information, synthesizing of new products and the modification of the world. Students must learn to use technology to analyze situations, gather relevant information, generate and evaluate creative ideas, pose tangible solutions and communicate their analyses, results and suggestions concisely.

\section{Standard 6: Science in Personal and Social Perspectives}

Applying science and technological innovations to personal and social issues such as health, populations, resources and environment helps students to develop decisionmaking skills. As students expand their conceptual horizons, they should recognize that collective individual actions manifest as societal issues. Students must recognize that society cannot afford to deal only with symptoms; personal and societal actions must be focused on elimination of the causes of problems. Students should recognize that unless imposed by legislation social change involves negotiation among different interest groups. Students must be allowed to encounter and examine social change in a variety of current and historical contexts.

\section{The Role of Technology}

West Virginia's vision for education includes the integration of technology throughout the curriculum so that all West Virginia students have the opportunity to develop technology skills that support learning. Successful learning environments provide opportunities for students to use education technology interwoven with relevant curricular content. West Virginia teachers are responsible for integrating technology appropriately in the students' learning environment. 


\section{Organization of the Science Program of Study}

The West Virginia Science Program of Study is drawn from the National Science Education Standards and the Project 2061 Benchmarks to promote a rigorous and challenging science curriculum. Through experiencing a spiraling, inquiry-based program of study, students in grades K-10 will develop foundational knowledge and skills in the physical sciences, the life sciences, and the earth and space sciences. To assure scientific literacy for all students, a coordinated, integrated approach is utilized in grades K-10. Students in the $11^{\text {th }}$ and $12^{\text {th }}$ grades participate in advanced in-depth laboratory-based elective courses designed to expand their conceptual understanding and enhance their research and laboratory skills.

\section{Source:}

Science Content Standards and Objectives for West Virginia Schools. Available from http://wvde.state.wv.us. 


\section{Appendix D}

\section{Semi-structured Interview Questions}

- Describe how you came to understand the science process skills.

- What would I see if I walked into your classroom while you were teaching the science process skills?

- Describe how you came to understand co-teaching.

- How do you think you would use the strategy of co-teaching in an elementary science class?

- Would you agree that the university methods course has prepared you for teaching in an elementary science classroom? Why or why not? 


\section{Appendix E}

\section{Consent and Information Form}

A Qualitative Study of Pre-service Teachers Using Co-teaching as a Method to Understand Scientific Process Skills to Teach Inquiry

\section{Introduction}

$\mathrm{I}$, , have been invited to participate in this research study which has been explained to me by Jennifer Carter, M.S., M.A. (principal investigator), and Edna Meisel, M.S., Ed.S. to fulfill the requirements for a doctoral dissertation in Curriculum and Instruction in the Department of Educational Theory and Practice at West Virginia University, under the direction of Dr. Patricia Obenauf.

\section{Purposes of the Study}

The purpose of the study is to learn more about how co-teaching can enhance the understanding of science process skills to teach inquiry in an elementary science classroom.

\section{Description of Procedures}

This study involves submitting my journal assignments and lesson plans to the instructor for use in the study. The journal assignments will be read by the instructor to ascertain my perceptions and thoughts on the science process skills, how I would use them in a classroom, and my thoughts on co-teaching and its uses in a classroom. My lesson plans will be evaluated using the attached rubric to see if I exhibit mastery, partial mastery, or unsatisfactory performance on writing and executing lesson plans. The comments made in regard to my performance may be used by the instructor to show general areas of strengths and weaknesses exhibited by all students in the study.

I further agree to an interview with my co-teaching partner at the end of the semester to discuss our thoughts and perceptions of science process skills and coteaching. I understand that my name will be used in the interview, but I will not be identified in the written study that will be published. The interview will be recorded on cassette tape and conducted by someone other than the instructor who is certified through the Office of Research and Compliance at WVU. time.

I may withdraw my permission to use my work or submit to an interview at any

\section{Risks and Discomforts}

There are no known or expected risks from participating in this study, except for the mild discomfort in being interviewed for up to a half an hour.

\section{Alternatives}

I understand that I do not have to participate in the study. 


\section{Benefits}

I understand that the benefit to me in this study is the enlightenment of a new teaching strategy, co-teaching, and an understanding of how to teach science process skills. There will also be a benefit to future teachers and present teachers who may read the results of this study.

\section{Contact Persons}

For more information about this research, I can contact Dr. Patricia Obenauf at 304-2933442, or her supervisor, Dr. Elizabeth Dooley at 304-293-3442. For information regarding my rights as a research subject, I may contact the Office of Research Compliance at 304-293-7073.

\section{Confidentiality}

I understand that my confidentiality cannot be kept from the instructor with regard to the journal assignments, lesson plans, or the interview. However, I do understand that my name will not appear in the written study. A pseudonym will be used for my name if my comments are used in the written study. The interviews will be recorded on cassette tapes. All tapes and copies of the journal assignments and lesson plans will be kept in a locked cabinet until the completion of the data analysis. The paper documents will be shredded and the tapes will be destroyed after the data has been analyzed.

\section{Voluntary Participation}

Participation in this study is voluntary. I understand that I am free to withdraw my consent to participate in this study at any time and that such refusal to participate will not affect my future care or my class standing or grade in the course. Refusal to participate or withdrawal will involve no penalty to me. I have been given the opportunities to ask questions about the research, and I have received answers concerning areas I did not understand. In the event new information becomes available that may affect my willingness to continue to participate in the study, this information will be given to me so I may make an informed decision about my participation.

Upon signing this form, I will receive a copy.

I willingly consent to participate in this research.

Signature of Subject or Subject's Legal Representative Date Time 


\section{JENNIFER C. MCCAIN}

December 2005

Doctor of Education, Curriculum and Instruction

West Virginia University

1. Dissertation titled "A Qualitative Study of Pre-service Teachers Using Co-teaching as a Method to Understand Scientific Process Skills to Teach Inquiry"

August 2000

Master of Arts, Leadership Studies

Marshall University Graduate College

May 1994

Master of Education, Secondary Education

Clemson University

December 1992

Clemson University

Bachelor of Science, Science Teaching

March 2005-present

Marshall University

Interim Director of Clinical Experiences

2. Manage all clinical student placements in the College of Education and Human Services working with teacher candidates, university supervisors, principals, and Board of Education administrators from the surrounding counties

3. Direct all university supervisors of the Level III teacher candidates including those in the School of Education and College of Fine Arts

4. Supervise Level II and III teacher candidates in surrounding public schools in elementary and secondary grade levels

5. Conduct weekly seminars addressing issues in teaching and learning for Level III teacher candidates including portfolio and capstone preparations

6. Place Level III teacher candidates for the following semester in appropriate grade level and content areas

7. Oversee Capstone Experiences for all teacher candidates completing their Level III placement

8. Handle all teacher candidate, supervisor, public school teacher, 
principal, or other administrator concerns and issues that arise in the placements at Level I, Level II, and Level III placements

9. Conduct internal evaluation of IBM Reinvent Grant focusing on the Partnership School Project

10. Participate on committees and in meetings or other activities as needed or directed by the Chair of the School of Education and/or the Associate Dean for Academic Programs

September 2000-March 2005

Marshall University

Supervisor of Clinical Experiences

11. Supervise Level II and III teacher candidates in surrounding public schools in elementary and secondary grade levels

12. Conduct weekly seminars addressing issues in teaching and learning for Level III teacher candidates including portfolio and capstone preparations

13. Participate in the Partnership School Project assisting the development of and sustaining of partnerships with approximately 8 schools

14. Conduct internal evaluation of IBM Reinvent Grant focusing on the Partnership School Project

15. Participate in and assist with the NCATE visit for accreditation of the Teacher Education program

16. Participate on committees and in meetings or other activities as needed or directed by the Chair of the School of Education and/or the Associate Dean for Academic Programs

August 1999-September 2000

Marshall University

Graduate Assistant

17. Directly assist the Associate Dean for the College of Education and Human Services

18. Organize and prepare for meeting and conferences held by the Dean's Office

19. Assist the Associate Dean with necessary tasks for Program Review and NCATE accreditation reports

August 1994-June 1999

Sullivan Middle School

Teacher, Eighth grade science

20. Teach Earth Science and integrated science at basic and advanced levels

21. Chair of the Science Fair Executive Committee each year for the presentation of students' work on science projects from sixth through eighth grade, organize all activities to culminate in Sullivan Middle School Family Night to showcase projects

Summers 1995-1999

Marshall University Graduate College 
Adjunct Instructor

22. Teach environmental science, physics, and integrated science to practicing teachers from Wood, Roane, McDowell, Raleigh, and Webster Counties in Master of Education programs

January 1996-December 1996

Winthrop University

Adjunct Instructor

23. Teach Earth Science to elementary, early childhood and special education majors, classes included hands-on laboratory and field experiences

PROFESSIONAL MEMBERSHIPS

West Virginia Science Teachers Association

Phi Delta Kappa

Human Participant Protections, Research Compliance Office, West Virginia University

Training, Charlotte Danielson Framework for Learning

Principal, K-12 ${ }^{\text {th }}$ grade, State of West Virginia, expired August 2002

Evaluation Leadership Institute, Center for Professional

Development, West Virginia

Teacher, Science, 7-12 ${ }^{\text {th }}$ grades, State of West Virginia, expired 2001

Teacher, Science, $7-12^{\text {th }}$ grades, State of South Carolina, expired 2000

APT, Assessing Performance in Teaching, State of South Carolina

Nonviolent Crisis Intervention Management, Rock Hill School

District

Multiple Intelligences/Learning Styles, Rock Hill School District

PROFESSIONAL ACTIVITIES

IBM Reinvent Grant Executive Committee

Partnership Schools Project Executive Advisory Board

Presenter, West Virginia Science Teachers Association, Snowshoe, West Virginia, Fall 2003, "Research in the Science Classroom" 
Co-Presenter, Association of Teacher Educators, Summer

Conference, Williamsburg, Virginia, August 3-7, 2002, "Preparing

Mathematics and Science Teachers through a Professional

Development Team Concept"

Co-Presenter, Eastern Educational Research Association, Hilton Head, South Carolina, February 14-17, 2001, "Self-Efficacy in the Teaching of Science"

Carter, W., Sottile, J., \& Carter, J. (2001, February). $\underline{\text { Science }}$ achievement and self-efficacy among middle school age children as related to student development. Paper presented at the annual conference of the Eastern Educational Research Association, Hilton Head, SC. 